\title{
ENTROPY GENERATION ON MHD FLOW OF POWELL-EYRING FLUID BETWEEN RADIALLY STRETCHING ROTATING DISK WITH DIFFUSION-THERMO AND THERMO-DIFFUSION EFFECTS
}

\author{
"Najeeb Alam KHAN, *Shahnila AZIZ, **Saif ULLAH \\ *Department of Mathematics, University of Karachi, Karachi 75270, Pakistan \\ ${ }^{*}$ Department of Mathematics, Government College University Lahore, 54000, Pakistan. \\ najeeb@uok.edu.pk, shahnilaaziz@yahoo.com, dr.saifullah@gcu.edu.pk
}

received 30 July 2015, revised 23 February 2017, accepted 6 March 2017

\begin{abstract}
An investigation is performed for an alyzing the effect of entropy generation on the steady, laminar, axisymmetric flow of an incompressible Powell-Eyring fluid. The flow is considered in the presence of vertically applied magnetic field between radially stretching rotating disks. The Energy and concentration equation is taking into account to investigate the heat dissipation, Soret, Dufour and Joule heating effects. To describe the considered flow non-dimensionalized equations, an exact similarity function is used to reduce a set of the partial differential equation into a system of non-linear coupled ordinary differential equation with the associated boundary conditions. Using homotopy analysis method (HAM), an analytic solution for velocity, temperature and concentration profiles are obtained over the entire range of the imperative parameters. The velocity components, concentration and temperature field are used to determine the entropy generation. Plots illustrate important results on the effect of physical flow parameters. Results obtained by means of HAM are then compared with the results obtained by using optimized homotopy analysis method (OHAM). They are in very good agreement.
\end{abstract}

Keywords: Axisymmetric flow, Entropy generation, Stretching disk, Powell-Eyring fluid, Diffusion

\section{INTRODUCTION}

Energy flux or diffusion of energy is produced by a composition gradient termed as Dufour effect or the diffusion-thermo effect, though mass flux or species differentiation emerging in an initially homogeneous mixture can be caused by a temperature gradient, embodies the Soret or thermal-diffusion effect. Whenever the transfer of heat and mass occurs then there exists density differences in the flow regime, abovementioned effects are momentous for the separation of isotope and mixture amongst gases of very light molecular weight such as hydrogen and helium and of medium molecular weight such as nitrogen and air. Due to the simultaneous occurrence of heat and mass transfer in a moving fluid, the association among the fluxes and the driving potentials might be of more complicated in nature. These effects substantially cover the areas, for instance, geothermal energy, nuclear waste disposal, hydrology etc. and deliberated as second-order phenomena. Many researchers considered the combined effect of Soret and Dufour effects as they are not of the smaller order of magnitude than the effect defined by Fourier's and Fick's laws. Diverse situations have been deliberated by modern researchers to gain insight regarding the non-Newtonian fluid flow rate and heat transfer on the stretching, rotating surfaces. Flow over inextensible moving surface was first proposed and investigated by Sakiadas (1961). In recent times a large number of researchers have been further extending the work of Sakiadas (1961) by considering various physical situations. Exact solution for twodimensional viscous boundary layer flow affected by linear stretching of the elastic flat surface was presented by Crane
(1970). Later Wang (1984) and Banks (1983) generalized the same problem for three-dimensional flows due to stretching sheet and to a power law stretching velocity respectively, the acquired result was no longer exact in such cases. In addition, Gupta and Gupta (1977) continued the Crane's problem by including mass suction and injection at the wall. Bataller (2007) observed the flow and heat transfer characteristics of the homogeneous secondgrade fluid over a non-isothermal stretching sheet in the presence of non-uniform internal heat generation. While the flow over stretching surface subject to an unvarying heat flux along with the temperature field was discussed by Grubka and Bobba (1985). On the other hand, Wang (1988) talked about the rotating fluid flow over the stretching surface. Fang (2007) further extended the problem of stretching surface to the combine effects of stretching and disk rotation. Fang and Zhang (2008) found the exact solution of Navier-Stokes equations for the flow between two stretching disks. A numerical study was conducted by Ashraf and Batool (2013) for the analysis of the axisymmetric steady flow of an electrically conducting micropolar fluid and heat transfer in the presence of magnetic field over a stretching disk. Turkyilmazoglu (2012) employed an extremely accurate spectral numerical integration scheme to examine the flow due to radially stretchable rotating disk of an electrically conducting fluid under the influence of vertically applied magnetic field. Moreover, for the first time power-law stretching rotating disk in the radial direction was pondered by Asghar et al. (2014). He used Lie group theory to calculate the symmetries of governing equations and then Munawar et al. (2011) presented analytic solution using optimal homotopy analysis method for the viscous fluid flow sandwiched between two stretching disks with slip boundaries and the effects of materi- 
al parameters on the quantities of physical interest. Ariel (2001) studied the viscoelastic fluid flow over a radially stretching disk wherein he obtained the perturbation and asymptotic solution for small and large Deborah number respectively. The considered flow is axisymmetric for both cases. The Unsteady axisymmetric flow over a radially stretching sheet has been obtained by Sajid et al. (2008) and he also found the series solution of considered flow and observed the heat transfer effect. A number of cases had been presented by Eckert and Drake (1097) wherein thermaldiffusion and diffusion-thermo effect cannot be neglected. Linear and non-linear stability analysis were carried out by Gaikwad (2007) for double diffusive convection with Soret and Dufour effects in a two component couple stress fluid layer. A numerical model to study the combined effect of Soret and Dufour effects and also the influence of hydromagnetic effect on convective slip flow, viscous dissipation, Ohmic heating, heat and mass transfer, the flow induced by a rotating disk was developed by Osalusi et al. (2008). Additionally, Afify (2009) worked for free convective heat and mass transfer characteristics over a stretching surface and also considered the suction or injection with Soret and Dufour effects. Tsai et al. (2009) presented heat and mass transfer analysis which had been designed for steady stagnation point flow through a porous medium over a uniform stretching surface by solving of continuity, momentum, energy and concentration equations using the numerical procedure. A numerical analysis using fourth order Runge-Kutta based on shooting method was conducted, on MHD slip flow of an electrically conducting Newtonian fluid over a porous rotating infinite disk with the consideration of thermal radiation effect, Soret and Dufour effects by Anjali et al. (2011). With the aim of reporting, Hayat et al. (2010) observed heat and mass transfer characteristics of the viscoelastic fluid, in consideration of Soret and Dufour diffusion effects on mixed convection boundary layer flow over a linearly stretching vertical surface in a porous medium. Rashidi et al. (2011) considered the thermal-diffusion and diffusion-thermo effects, viscous dissipation, Ohmic heating, MHD convective and partial slip effects due to rotating disk flow of homogeneous fluid. He derived solution in the form of exponentially-decaying series functions via homotopy analysis method. Khan et al. (2014) have discussed the unsteady flow of couple stress fluid over a rotating disk in which they observed the different behavior of couple stresses. Powell and Eyring (1944) proposed the mechanism for the relaxation theory of viscosity. Khan et al. (2014) presented MHD flow of PowellEyring fluid due a rotating disk under the influential external magnetic field and discussed analytically using the semi-analytical method.

In thermodynamical systems, flow and heat transfer process losses useful energy which can cause great disorder and controlling of this disorder is the core interest of modern engineers and scientists. Analysis of second law of thermodynamics is a useful tool by which one can secure wastage of energy, predict the performance and fully utilize energy resources by minimizing the irreversibility, measured by entropy generation and get the optimal and improved efficiency of the thermal system. Many researchers employed the approach of minimizing entropy generation by taking diverse geometrical arrangements and many engineers have designed a thermal system to optimize, for instance, Butt et al. (2012) showed that entropy generation rate can be abridged and precise as the slip which is present over a vertical plate. Guo et al. (2011) numerically investigated laminar flow in a microchannel. $\mathrm{Li}$ et al. (2011) conducted local entropy generation analysis based on two-dimensional, two-phase fuel cells. For more recent studies see ref. (Butt and Ali, 2014, Rashidi et. Al., 2014, Torabi and Zhang, 2015,Parvin and Chamkha, 2014, Mahian et. Al., 2013, Shateyi et. Al., 2015, Abolbashari et. Al., 2014, Bhatti et. Al., 2016).

The flow of non-Newtonian fluid over stretching and rotating surfaces has been focused by scientists and engineers as it has extensively important applications. Phenomena's in which such type of flows occur are designing cooling systems for liquid metals, thermal-power-generating systems, flow meters, gas turbines, medical equipment, metallurgical and polymer extrusion of sheet materials, rolling of plastic films etc. Furthermore, the spinning of fibers, glass blowing, crystalline materials and continuous casting of metals, involve the flow above the stretching surfaces.

Stimulated by the aforementioned reference works and the various industrial and engineering applications of MHD flow of non-Newtonian fluids over a stretching rotating disk, the current article aims at investigating the Soret and Dufour effect on steady MHD flow of Powell-Eyring fluid in the presence of uniformly applied magnetic field. We propose to extend the problem of Gorder et al. (2010) and consider the electrically conducting nonNewtonian Powell-Eyring fluid between two stretching disks with heat and mass transfer. Moreover, we are taking entropy generation analysis into account in order to discuss the second law of thermodynamics. Invoking suitable similarity transformations, the system of nonlinear partial differential equations reduced into nonlinear ordinary differential equations and then deciphered anaIytically for the velocity, temperature and the concentration distributions by employing a powerful, easy-to-use technique, namely homotopy analysis method presented by Liao $(2003,2004)$. Firstly we computed the series solution and discussed its convergence. Obtained results using HAM are compared with results of optimized homotopy analysis method (OHAM). Lastly, the graphs are sketched for the variations of different flow governing parameters on the velocity, temperature and concentration profiles are addressed.

\section{FLOW ANALYSIS OF THE PROBLEM}

Effects of Soret and Dufour on steady, laminar, hydromagnetic, axisymmetric flow of non-Newtonian Powell-Eyring fluid in between stretching rotating disks studied. Disks are separated vertically by distance $\mathrm{c}$ and both of the disks are stretched outwardly with the velocity proportional to the radius of the disk. Considered flow is defined in non-rotating cylindrical polar coordinates $(\mathrm{r}, \psi, \mathrm{z})$ with $\mathrm{z}$ is chosen as the vertical axis, and as $r$ and $\psi$ are radial and tangential axes. $(\mathrm{u}, \mathrm{v}, \mathrm{w})$ are assumed to be the velocity components in the direction of cylindrical polar coordinates $(\mathrm{r}, \psi, \mathrm{z})$ respectively. At the plane, $\mathrm{z}=0$ the lower disk is fixed, while the upper disk is fixed at the plane $\mathrm{z}=\mathrm{c}$. A transverse uniformly distributed magnetic field with a constant magnetic flux density B is applied vertically to the surface of the disk as shown in Fig. 1.

The external electric field and the electric field due to the polarization of charges are assumed to be negligible. Furthermore, the magnetic Reynolds number Re for the considered flow is a number much smaller than the fluid Reynolds number $R e_{m}$ as the induced magnetic field is neglected. The continuity, momentum, energy and concentration equations governing the magnetohydrodynamics flow of Powell-Eyring fluid for the problem with the related boundary condition can be written in the form: 
$\frac{\partial u}{\partial \mathrm{r}}+\frac{u}{\mathrm{r}}+\frac{\partial w}{\partial \mathrm{z}}=0$

$u \frac{\partial u}{\partial \mathrm{r}}-\frac{v^{2}}{\mathrm{r}}+w \frac{\partial u}{\partial \mathrm{z}}=-\frac{1}{\rho} \frac{\partial p}{\partial \mathrm{r}}$

$$
+\frac{1}{\rho}\left(\frac{\partial S_{r r}}{\partial \mathrm{r}}+\frac{\partial S_{z r}}{\partial \mathrm{z}}+\left(\frac{S_{r r}-S_{\psi \psi}}{\mathrm{r}}\right)\right)-\sigma B u
$$

$u \frac{\partial v}{\partial \mathrm{r}}-\frac{u v}{\mathrm{r}}+w \frac{\partial v}{\partial \mathrm{z}}$

$$
=\frac{1}{\rho}\left(\frac{\partial S_{r \psi}}{\partial \mathrm{r}}+\frac{\partial S_{z \psi}}{\partial \mathrm{z}}+2 \frac{S_{r \psi}}{\mathrm{r}}\right)-\sigma B v
$$

$u \frac{\partial w}{\partial \mathrm{r}}+w \frac{\partial w}{\partial \mathrm{z}}=-\frac{1}{\rho} \frac{\partial \mathrm{p}}{\partial \mathrm{z}}+\frac{1}{\rho}\left(\frac{\partial S_{r z}}{\partial \mathrm{r}}+\frac{\partial S_{z z}}{\partial \mathrm{z}}+\frac{S_{r z}}{\mathrm{r}}\right)$

$u \frac{\partial T}{\partial \mathrm{r}}+w \frac{\partial T}{\partial \mathrm{z}}=\frac{\mathrm{k}}{\rho \mathrm{Cp}}\left(\frac{\partial^{2} T}{\partial \mathrm{r}^{2}}+\frac{1}{r} \frac{\partial T}{\partial \mathrm{r}}+\frac{\partial^{2} T}{\partial \mathrm{z}^{2}}\right)$

$+\frac{\text { Dm Kt }}{\rho \operatorname{Cs~Cp}}\left(\frac{\partial^{2} C}{\partial \mathrm{r}^{2}}+\frac{1}{r} \frac{\partial C}{\partial \mathrm{r}}+\frac{\partial^{2} C}{\partial \mathrm{z}^{2}}\right)+\frac{\sigma B^{2}}{\rho C p}\left(u^{2}+v^{2}\right)$

$$
+\frac{1}{\rho C p}\left(\begin{array}{c}
S_{r r}\left(\frac{\partial u}{\partial \mathrm{r}}\right)+S_{\psi \psi}\left(\frac{u}{\mathrm{r}}\right)+S_{z z}\left(\frac{\partial w}{\partial \mathrm{z}}\right) \\
+S_{r z}\left(\frac{\partial u}{\partial \mathrm{z}}+\frac{\partial w}{\partial \mathrm{r}}\right)+S_{r \psi}\left(\frac{\partial v}{\partial \mathrm{r}}-\frac{\mathrm{v}}{\mathrm{r}}\right) \\
+S_{\psi z}\left(\frac{\partial v}{\partial \mathrm{z}}\right)
\end{array}\right)
$$

$u \frac{\partial C}{\partial \mathrm{r}}+w \frac{\partial C}{\partial \mathrm{z}}=\operatorname{Dm}\left(\frac{\partial^{2} C}{\partial \mathrm{r}^{2}}+\frac{1}{r} \frac{\partial C}{\partial \mathrm{r}}+\frac{\partial^{2} C}{\partial \mathrm{z}^{2}}\right)$

$$
+\frac{\mathrm{Dm} \mathrm{Kt}}{\mathrm{Tm}}\left(\frac{\partial^{2} T}{\partial \mathrm{r}^{2}}+\frac{1}{r} \frac{\partial T}{\partial \mathrm{r}}+\frac{\partial^{2} T}{\partial \mathrm{z}^{2}}\right)
$$

$u(r, 0)=l r, \quad u(r, c)=\operatorname{lr} \varepsilon$,

$$
v(r, 0)=v(r, c)=0,
$$

$w(r, 0)=w(r, c)=0, \quad p(r, 0)=\frac{l \rho v \beta}{4} \frac{r^{2}}{c^{2}}$

where:

$V(r, z)=\left(\begin{array}{l}u \\ v \\ w\end{array}\right), \quad S_{i j}=\mu \nabla V+\frac{1}{\varepsilon}\left(\frac{1}{b} \nabla V-\frac{1}{6}\left(\frac{1}{b} \nabla V\right)^{3}\right)$,

$i, j=r, \psi, z, \quad\left|\frac{1}{b} \nabla \mathrm{V}\right| \ll 1$

$\mathrm{S}_{\mathrm{ij}}$ is the extra stress tensor for the Powell-Eyring model, $\mathrm{V}$ is the velocity, $\varepsilon$ and $b$ are the material constant of the PowellEyring fluid model, $\rho \quad \sigma$ and $v$ are the density, electric conductivity and viscosity of the fluid, $l$ is a stretching disk parameter, $\eta$ is an unknown parameter to be determined later. Using suitable similarity transformation:

$u=\operatorname{lr} F(\Lambda), \quad v=0, \quad w=l c H(\Lambda)$,

$p=l \mu\left(P(\Lambda)+\frac{\eta}{4} \frac{r^{2}}{c^{2}}\right), \quad \Lambda=\frac{z}{c^{\prime}}$

$T=T_{0}+\left(T_{1}-T_{0}\right) \theta(\Lambda)$,

$$
C=C_{0}+\left(C_{1}-C_{0}\right) \phi(\Lambda)
$$

As we see that the equation of continuity is identically satisfied by using Eq. (8) and yields the relation:

$2 F(\Lambda)+H^{\prime}(\Lambda)=0$
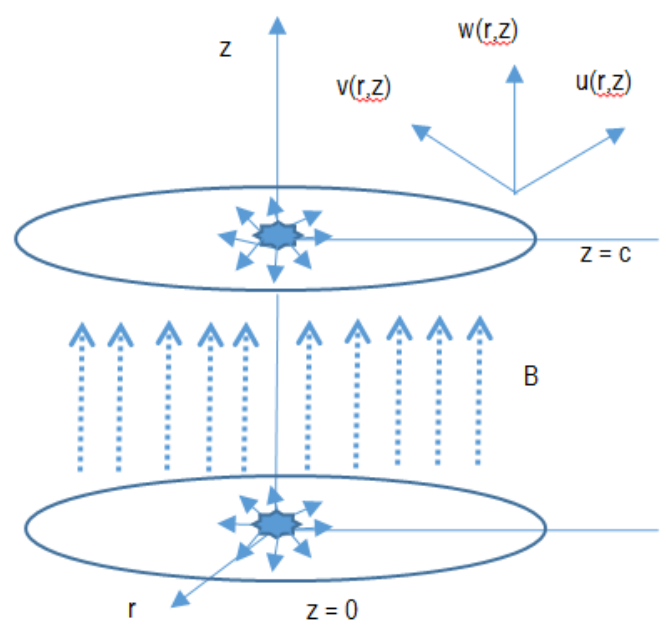

Fig. 1. Physical model of considered flow

Now using Eqs. (6) and (7) in momentum, energy and concentration equations we get:

$$
\begin{aligned}
& \frac{\eta}{2}+\text { Ha } F(\Lambda)+\operatorname{Re}\left((F(\Lambda))^{2}-H(\Lambda) F^{\prime}(\Lambda)\right) \\
& +(1+N) F^{\prime \prime}(\Lambda)-2 N L\left(\begin{array}{c}
6 F(\Lambda)\left(F^{\prime}(\Lambda)\right)^{2} \\
+2 c F^{\prime \prime}(\Lambda) \\
+\left(H^{\prime}(\Lambda)\right)^{2} F^{\prime \prime}(\Lambda) \\
+2 F^{\prime}(\Lambda) H^{\prime}(\Lambda) H^{\prime \prime}(\Lambda) \\
+\frac{3}{2} \delta\left(F^{\prime}(\Lambda)\right)^{2} F^{\prime \prime}(\Lambda)
\end{array}\right)
\end{aligned}
$$$$
=0
$$

$P^{\prime}(\Lambda)+\operatorname{Re} H(\Lambda) H^{\prime}(\Lambda)$

$$
+2 N L\left(\begin{array}{c}
4(F(\Lambda))^{2} F^{\prime}(\Lambda)+8 F(\Lambda) F^{\prime}(\Lambda) H^{\prime}(\Lambda) \\
+2 F(\Lambda)\left(H^{\prime}(\Lambda)\right)^{2}+H^{\prime \prime}(\Lambda)(F(\Lambda))^{2} \\
+6 H^{\prime \prime}(\Lambda)\left(H^{\prime}(\Lambda)\right)^{2}+\delta\left(F^{\prime}(\Lambda)\right)^{3} \\
+F^{\prime}(\Lambda) H^{\prime}(\Lambda) F^{\prime \prime}(\Lambda)
\end{array}\right)=0
$$

$\theta^{\prime \prime}(\Lambda)-\operatorname{Pr} \operatorname{Re} H(\Lambda) \theta^{\prime}(\Lambda)-\mathrm{Ha} \operatorname{Br} \operatorname{Re}(F(\Lambda))^{2}$ $+\operatorname{Du} \operatorname{Pr} \phi^{\prime \prime}(\Lambda)-(1$

$$
+N) \operatorname{Br}\left(\begin{array}{c}
\frac{4}{\delta}(F(\Lambda))^{2}+\left(F^{\prime}(\Lambda)\right)^{2} \\
+\frac{2}{\delta}\left(H^{\prime}(\Lambda)\right)^{2}
\end{array}\right)
$$$$
+N \operatorname{LBr}\left(\begin{array}{c}
8(F(\Lambda))^{2}\left(F^{\prime}(\Lambda)\right)^{2}+4\left(F^{\prime}(\Lambda)\right)^{2}\left(H^{\prime}(\Lambda)\right)^{2} \\
+\frac{16}{\delta}(F(\Lambda))^{4}+\delta^{2}\left(F^{\prime}(\Lambda)\right)^{4} \\
+16\left(H^{\prime}(\Lambda)\right)^{2}(F(\Lambda))^{2}+4\left(F^{\prime}(\Lambda)\right)^{4}
\end{array}\right)
$$

$=0$

$\phi^{\prime \prime}(\Lambda)+\operatorname{SrSc} \theta^{\prime \prime}(\Lambda)-\operatorname{Re}$ Le $\operatorname{Pr} H(\Lambda) \phi(\Lambda)=0$

with boundary conditions:

$H(0)=H(1)=0, \quad F(0)=1, \quad F(1)=\gamma$

and:

$P(0)=0, \theta^{\prime}(0)=0, \theta(1)=1, \phi^{\prime}(0)=0$, $\phi(1)=1$ 
Using Eq. (9) in Eq. (10) and by taking Eq. (14) with that, it can be seen that the system is overdetermined, so differentiation of Eq. (10) produces more compact expression:

$$
\begin{gathered}
(1+N) H^{\prime \prime \prime \prime}(\Lambda)-\text { Ha } \operatorname{Re} H^{\prime \prime}(\Lambda)-\operatorname{Re} H(\Lambda) H^{\prime \prime \prime}(\Lambda) \\
-N L\left(\begin{array}{c}
7\left(H^{\prime \prime}(\Lambda)\right)^{3}+20 H^{\prime}(\Lambda) H^{\prime \prime}(\Lambda) H^{\prime \prime \prime}(\Lambda) \\
+3\left(H^{\prime}(\Lambda)\right)^{2} H^{\prime \prime \prime \prime}(\Lambda)+\frac{3}{2} \delta\left(H^{\prime \prime \prime}(\Lambda)\right)^{2} H^{\prime \prime}(\Lambda) \\
+\frac{3}{4} \delta\left(H^{\prime \prime}(\Lambda)\right)^{2} H^{\prime \prime \prime \prime}(\Lambda) \\
=0
\end{array}\right)
\end{gathered}
$$

which is still subjected to the boundary conditions:

$H(0)=H(1)=0, \quad H^{\prime}(0)=-2, \quad H^{\prime}(1)=-2 \gamma$

where $B r=\operatorname{PrEc}$ is the Brinkman number, $D u=$ $\frac{D m K t\left(C_{1}-C_{0}\right)}{v C p C s\left(T_{1}-T_{0}\right)}$ is the Dufour number, $E c=\frac{l^{2} r^{2}}{C p\left(T_{1}-T_{o}\right)}$ is the Eckert number, $H a=\frac{\sigma B^{2}}{\rho l}$ is the Hartman number, $L e=\frac{k}{\rho C p D m}$ is the Lewis number, $L=\frac{l^{2}}{6 b^{2}} \quad$ and $\mathrm{N}=\frac{1}{\mu \varepsilon \mathrm{b}} \quad$ are nonNewtonian Powell-Eyring parameters, $\operatorname{Pr}=\frac{\mu C p}{k}$ is the Prandtl number, $R e=\frac{l c^{2}}{v}$ is the wall stretching Reynolds number, $S c=\frac{l c^{2}}{D m}$ is the Schmidt number, $S r=\frac{D m K t\left(T_{1}-T_{0}\right)}{v T m\left(C_{1}-C_{0}\right)}$ is the Soret number, Ratio of the stretching velocity of the upper disk to the lower disk is considered to be $\gamma$ and $\delta=\frac{r^{2}}{c^{2}}$ is the dimensionless ratio of the disk to the distance between them.

The local skin-friction coefficients $\mathrm{C}_{\mathrm{f}}$ at lower and upper disk and the heat transfer coefficient in terms of local Nusselt number $\mathrm{Nu}$ are defined as under:

$C_{f}=-\left.\frac{1}{2} \frac{1}{\sqrt{\operatorname{Re}}} H^{\prime \prime}(\Lambda)\left(\begin{array}{c}1+N-3 N L\left(H^{\prime \prime}(\Lambda)\right)^{2} \\ -\operatorname{ReN} L\left(\begin{array}{c}\frac{1}{4}\left(H^{\prime \prime}(\Lambda)\right)^{2} \\ +\left(G^{\prime}(\Lambda)\right)^{2}\end{array}\right)\end{array}\right)\right|_{\Lambda=0, c}$

$\mathrm{Nu}=-\frac{\left.r\left(\frac{\partial T}{\partial z}\right)\right|_{z=0}}{\left(T_{1}-T_{0}\right)}$

An unknown parameter can be determine using calculated value of $F(\Lambda)$ and $H(\Lambda)$.

$$
\begin{aligned}
& \eta=-2\left(\operatorname{HaF}(\Lambda)+\operatorname{Re}\left((F(\Lambda))^{2}-H(\Lambda) F^{\prime}(\Lambda)\right)\right) \\
& -2(1+N) F^{\prime \prime}(\Lambda)+4 N L\left(\begin{array}{c}
6 F(\Lambda)\left(F^{\prime}(\Lambda)\right)^{2} \\
+2 F^{\prime \prime}(\Lambda)(F(\Lambda))^{2} \\
+F^{\prime \prime}(\Lambda)\left(H^{\prime}(\Lambda)\right)^{2} \\
+2 F^{\prime}(\Lambda) H^{\prime}(\Lambda) H^{\prime \prime}(\Lambda) \\
3 \\
+\frac{3}{2} \delta F^{\prime \prime}(\Lambda)\left(F^{\prime}(\Lambda)\right)^{2}
\end{array}\right)
\end{aligned}
$$

\section{ENTROPY GENERATION}

Entropy is a decisive physical concept originated from this law. The substantial consequence of altercation of momentum and energy as the fluid flows within the boundary is entropy generation succeeding the thermodynamic irreversibility of the system. This is the decisive concept, whose origin is second order law of thermodynamics. One part of entropy generation is due to heat transfer in the direction of temperature gradients, whereas others may be due to fluid friction irreversibility, Joule heating, viscous heating. Conferring to (Bejan, 1982, 1996, Arikoglu and Ozkol, 2008) the volumetric entropy generation rate for the considered axisymmetric flow of Powell-Eyring fluid in the presence of magnetic field is given by:

$S_{G}$

$$
\begin{gathered}
=\frac{1}{T_{0}}\left(\begin{array}{c}
\left(\frac{\partial u}{\partial r}\right) S_{r r}+\left(\frac{u}{r}\right) S_{\psi \psi}+\left(\frac{\partial w}{\partial z}\right) S_{z z} \\
+\left(\frac{\partial u}{\partial z}+\frac{\partial w}{\partial r}\right) S_{r z}+\left(\frac{\partial v}{\partial r}-\frac{v}{r}\right) S_{r \psi}+\left(\frac{\partial v}{\partial z}\right) S_{\psi z}
\end{array}\right) \\
+\frac{k}{\left(T_{0}\right)^{2}}\left(\left(\frac{\partial T}{\partial r}\right)^{2}+\left(\frac{\partial T}{\partial z}\right)^{2}\right)+\frac{\sigma B}{T_{0}}\left(u^{2}+v^{2}\right)
\end{gathered}
$$

As seen in above equation that the entropy generation equation consists of three parts. The first and second part refer the local entropy generation caused by fluid friction irreversibility and heat transfer irreversibility while the third part signifies magnetic field effects.

In terms of dimensionless variable, entropy generation number defines as the ratio between the actual entropy generation rate and the characteristic entropy generation rate. By using the transformation function, defined in Eq. (8), the entropy generation number for the considered flow problem turn out to be:

$$
\begin{aligned}
N_{G}=\frac{S_{G}}{S_{G 0}}=\frac{4 \mathrm{Br}}{\delta} & (F(\Lambda))^{2}+\frac{2 \mathrm{Br}}{\delta}\left(H^{\prime}(\Lambda)\right)^{2} \\
+ & \operatorname{Br}\left(F^{\prime}(\Lambda)\right)^{2}
\end{aligned}
$$

$+\lambda\left(\theta^{\prime}(\Lambda)\right)^{2}+$ Ha $\operatorname{Re} \operatorname{Br}(F(\Lambda))^{2}$

where: $\lambda=\frac{T_{1}-T_{0}}{T_{0}}$ and $S_{G 0}=\frac{k\left(T_{1}-T_{0}\right)}{c^{2} T_{0}}$.

It can be seen from Eq. (18) that raise in the Brinkman number will result in the increase in entropy generation due to fluid friction irreversibility. Similarly as $\alpha$ and Hartmann number increases in the entropy generation due to heat transfer and the magnetic effect increases respectively. Bejan number provides information regarding irreversibility mechanism which plays a vital role in analyzing entropy generation. For the considered problem this dimensionless parameter ratio can be written as:

$\mathrm{Be}=\frac{\lambda\left(\theta^{\prime}(\Lambda)\right)^{2}}{\left(\begin{array}{c}\frac{4 \mathrm{Br}}{\delta}(F(\Lambda))^{2}+\frac{2 \mathrm{Br}}{\delta}\left(H^{\prime}(\Lambda)\right)^{2} \\ +\operatorname{Br}\left(F^{\prime}(\Lambda)\right)^{2}+\lambda\left(\theta^{\prime}(\Lambda)\right)^{2} \\ +\mathrm{Ha} \operatorname{Re} \operatorname{Br}(F(\Lambda))^{2}\end{array}\right)}$ 


\section{HOMOTOPY ANALYTIC SOLUTION}

In the past two decades, for analytical solution of lots of nonlinear problems in science and engineering, many researchers have applied Homotopy analysis method (HAM) successfully. HAM is employed to solve Eqs. (12), (13) and (16) subject to the boundary conditions (15) and (17). HAM solutions are an infinite power series for suitable initial approximation, which can be in turn, expressed in a closed form. Initial approximations and auxiliary linear operators have been selected as follows:

$H(\Lambda)=-2 \Lambda+2(2+\gamma) \Lambda^{2}-2(1+\gamma) \Lambda^{3}$,

$\theta_{0}(\Lambda)=\Lambda^{2}$ and $\theta_{0}(\Lambda)=\Lambda^{2}$

$\mathcal{L}_{1}(\mathrm{H})=\frac{d^{4} H}{d \Lambda^{4}}, \mathcal{L}_{2}(\theta)=\frac{d^{2} \theta}{d \Lambda^{2}}$ and $\mathcal{L}_{3}(\mathrm{H})=\frac{d^{2} \phi}{d \Lambda^{2}}$

which was found to be quite efficient and has the property that:

$\left\{\begin{array}{c}\mathcal{L}_{1}\left[C_{1}+C_{2} \Lambda+C_{3} \Lambda^{2}+C_{4} \Lambda^{3}\right]=0 \\ \mathcal{L}_{2}\left[C_{5}+C_{6} \Lambda\right]=0 \\ \mathcal{L}_{3}\left[C_{7}+C_{8} \Lambda\right]=0\end{array}\right.$

With $C_{n}, n=1,2 \ldots 8$ are arbitrary constants. Now we construct system of zeroth order deformation equation associated with the considered flow which is respectively, given by:

$$
\begin{gathered}
(1-x) \mathcal{L}_{1}\left[H(\Lambda, x)-H_{0}(\Lambda)\right]=x \hbar N_{H}[H(\Lambda, x)], \\
(1-x) \mathcal{L}_{2}\left[\theta(\Lambda, x)-\theta_{0}(\Lambda)\right] \\
=x \hbar N_{\theta}[H(\Lambda, x), F(\Lambda, x), \phi(\Lambda, x)], \\
(1-x) \mathcal{L}_{3}\left[\phi(\Lambda, x)-\phi_{0}(\Lambda)\right] \\
=x \hbar N_{\phi}[H(\Lambda, x), \theta(\Lambda, x)] .
\end{gathered}
$$

Subject to the boundary conditions:

$$
\begin{gathered}
H(0, x)=0, H(1, x)=0, H^{\prime}(0, x)=-2, H^{\prime}(1, x) \\
=-2 \gamma
\end{gathered}
$$

in which the nonlinear operators $\mathrm{N}_{\mathrm{H}}, \mathrm{N}_{\theta}$ and $\mathrm{N}_{\phi}$ are defined as:

$N_{H}[H(\Lambda, x)]=(1+N) H^{\prime \prime \prime \prime}(\Lambda)-$ Ha Re $H^{\prime \prime}(\Lambda)$

$-\operatorname{Re} H(\Lambda) H^{\prime \prime \prime}(\Lambda)$

$-N L\left(\begin{array}{c}7\left(H^{\prime \prime}(\Lambda)\right)^{3}+20 H^{\prime}(\Lambda) H^{\prime \prime}(\Lambda) H^{\prime \prime \prime}(\Lambda) \\ +3\left(H^{\prime}(\Lambda)\right)^{2} H^{\prime \prime \prime \prime}(\Lambda)+\frac{3}{2} \delta\left(H^{\prime \prime \prime}(\Lambda)\right)^{2} H^{\prime \prime}(\Lambda) \\ +\frac{3}{4} \delta\left(H^{\prime \prime}(\Lambda)\right)^{2} H^{\prime \prime \prime \prime}(\Lambda)\end{array}\right)$

$N_{\theta}[\mathrm{H}(\Lambda, \mathrm{x}), F(\Lambda, \mathrm{x}), \phi(\Lambda, \mathrm{x})]$

$-\mathrm{Ha} \operatorname{Br} \operatorname{Re}(F(\Lambda))^{2}+D u \operatorname{Pr} \phi^{\prime \prime}(\Lambda)$

$-(1+N) B r\left(\frac{4}{\delta}(F(\Lambda))^{2}+\left(F^{\prime}(\Lambda)\right)^{2}+\frac{2}{\delta}\left(H^{\prime}(\Lambda)\right)^{2}\right)$

$+N L B r\left(\begin{array}{c}8(F(\Lambda))^{2}\left(F^{\prime}(\Lambda)\right)^{2}+4\left(F^{\prime}(\Lambda)\right)^{2}\left(H^{\prime}(\Lambda)\right)^{2} \\ +\frac{16}{\delta}(F(\Lambda))^{4}+\delta^{2}\left(F^{\prime}(\Lambda)\right)^{4} \\ +16\left(H^{\prime}(\Lambda)\right)^{2}(F(\Lambda))^{2}+4\left(F^{\prime}(\Lambda)\right)^{4}\end{array}\right)$

$$
\begin{aligned}
N_{\phi}[H(\Lambda, x), \theta(\Lambda, x)] & =\phi^{\prime \prime}(\Lambda)+\operatorname{SrSc} \theta^{\prime \prime}(\Lambda) \\
& -\operatorname{Re} \operatorname{Le} \operatorname{Pr} H(\Lambda) \phi^{\prime}(\Lambda)
\end{aligned}
$$

Where parameter $x \quad x$ in above equations represents an embedding parameter defined in the regime $[0,1]$. We have

$$
\begin{array}{ccc}
H(\Lambda, 0)=H_{0}(\Lambda), & H(\Lambda, 1)=H(\Lambda), \\
\theta(\Lambda, 0)=\theta_{0}(\Lambda), & \theta(\Lambda, 1)=\theta(\Lambda), \\
\phi(\Lambda, 0)=\phi_{0}(\Lambda), & \phi(\Lambda, 1)=\phi(\Lambda)
\end{array}
$$

Therefore as $\mathrm{x}$ varies from 0 to $1, \mathrm{H}(\Lambda, \mathrm{x}), \theta(\Lambda, \mathrm{x})$ and $\phi(\Lambda, \mathrm{x})$ continuously vary from $\mathrm{H}_{0}(\Lambda)$ to $\mathrm{H}(\Lambda), \theta_{0}(\Lambda)$ to $\theta(\Lambda)$ and $\phi_{0}(\Lambda)$ to $\phi(\Lambda)$. This continuous variation is known as deformation in topology. By Taylor's theorem and equation (32) yields the relations.

$$
\begin{gathered}
H(\Lambda ; x)=H_{0}(\Lambda)+\sum_{i=1}^{\infty} H_{j}(\Lambda) x^{j} \\
\theta(\Lambda ; x)=\theta_{0}(\Lambda)+\sum_{i=1}^{\infty} \theta_{j}(\Lambda) x^{j} \\
\phi(\Lambda ; x)=\phi_{0}(\Lambda)+\sum_{i=1}^{\infty} \phi_{j}(\Lambda) x^{j}
\end{gathered}
$$

where:

$$
\begin{aligned}
& H_{j}(\Lambda)=\left.\frac{1}{j !} \frac{\partial^{j} H(\Lambda ; x)}{\partial x^{j}}\right|_{x=0}, \quad \theta_{j}(\Lambda)=\left.\frac{1}{j !} \frac{\partial^{j} \theta(\Lambda ; x)}{\partial x^{j}}\right|_{x=0}, \\
& \phi_{j}(\Lambda)=\left.\frac{1}{j !} \frac{\partial^{j} \phi(\Lambda ; x)}{\partial x^{j}}\right|_{x=0} .
\end{aligned}
$$

The convergence of the series presented in Eqs. (33) is contingent only on auxiliary parameter i.e. $\hbar$ as mentioned by Liao (2004), and assumed that this auxiliary parameter is carefully chosen such that the series (33) converges at $\mathrm{x}=1$ then by reason of Eq. (32) we have:

$$
\begin{aligned}
& H(\Lambda ; x)=H_{0}(\Lambda)+\sum_{i=1}^{\infty} H_{j}(\Lambda), \\
& \theta(\Lambda ; x)=\theta_{0}(\Lambda)+\sum_{i=1}^{\infty} \theta_{j}(\Lambda) \\
& \phi(\Lambda ; x)=\phi_{0}(\Lambda)+\sum_{i=1}^{\infty} \phi_{j}(\Lambda) .
\end{aligned}
$$

Now for the $j^{\text {th }}$ order deformation equations, differentiating Eq. (27) $j$-times with respect to $x$ divided by $j$ ! and then set $x=0$ one obtain

$$
\begin{gathered}
\mathcal{L}_{1}\left[H_{j}(\Lambda)-\zeta H_{j-1}(\Lambda)\right]=\hbar \mathcal{R}_{H}^{j}(\Lambda), \\
\mathcal{L}_{2}\left[\theta_{j}(\Lambda)-\zeta \theta_{j-1}(\Lambda)\right]=\hbar \mathcal{R}_{\theta}^{j}(\Lambda), \\
\mathcal{L}_{3}\left[\phi_{j}(\Lambda)-\zeta \phi_{j-1}(\Lambda)\right]=\hbar \mathcal{R}_{\phi}^{j}(\Lambda) .
\end{gathered}
$$

with boundary condition:

$$
\begin{aligned}
& H(0, x)=0, \quad H(1, x)=0, \quad H^{\prime}(0, x)=-2, \\
& H(1, x)=-2 \gamma, \quad \theta^{\prime}(0, x)=0, \quad \theta(1, x)=1, \\
& \phi^{\prime}(0, x)=0, \quad \phi(1, x)=1
\end{aligned}
$$


Here $\zeta_{\mathrm{j}}=\left\{\begin{array}{l}0, \mathrm{j} \geq 1 \\ 1, \quad \mathrm{j}>1\end{array}\right.$ and $\mathcal{R}_{\mathrm{H}}^{\mathrm{j}}, \mathcal{R}_{\theta}^{\mathrm{j}}$ and $\mathcal{R}_{\phi}^{\mathrm{j}}$ are respectively given:

$\mathcal{R}_{H}^{j}=(1+N) H_{j-1}^{\prime \prime \prime}-H a R e H_{j-1}^{\prime \prime}-R e \sum_{i=0}^{j-1} H_{i} H_{j-1-i}^{\prime \prime \prime}$

$$
-L N\left(\begin{array}{c}
7 \sum_{i=0}^{j-1} H_{j-1-i}^{\prime \prime} \sum_{m=0}^{i} H_{i-m}^{\prime \prime} H_{m}^{\prime \prime} \\
+20 \sum_{i=0}^{j-1} H_{j-1-i}^{\prime} \sum_{m=0}^{i} H_{i-m}^{\prime \prime} H_{m}^{\prime \prime} \\
+3 \sum_{i=0}^{j-1} H_{j-1-i}^{\prime \prime \prime} \sum_{m=0}^{i} H_{i-m}^{\prime} H_{m}^{\prime} \\
+\frac{3}{2} \delta \sum_{i=0}^{j-1} H_{j-1-i}^{\prime \prime} \sum_{m=0}^{i} H_{i-m}^{\prime \prime \prime} H_{m}^{\prime \prime \prime} \\
+\frac{3}{4} \delta \sum_{i=0}^{j-1} H_{j-1-i}^{\prime \prime \prime} \sum_{m=0}^{i} H_{i-m}^{\prime \prime} H_{m}^{\prime \prime}
\end{array}\right)
$$

$\mathcal{R}_{\theta}^{j}=\theta_{j-1}^{\prime \prime}-\operatorname{Pr} R e \sum_{i=0}^{j-1} H_{i} \theta_{j-1-i}^{\prime}+\operatorname{Du} \operatorname{Pr} \phi_{j-1}^{\prime \prime}$

$-\frac{1}{4} \mathrm{HaBr} \operatorname{Re} \sum_{i=0}^{j-1} H_{i}^{\prime} H_{j-1-i}^{\prime}$

$-\operatorname{Br}(1+N)\left(\frac{3}{\delta} \sum_{i=0}^{j-1} H_{i}^{\prime} H_{j-1-i}^{\prime}+\frac{1}{4} \sum_{i=0}^{j-1} H_{i}^{\prime \prime} H_{j-1-i}^{\prime \prime}\right)$

$+L N \mathrm{Br}\left(\begin{array}{c}\frac{3}{2} \sum_{i=0}^{j-1} H_{j-1-i}^{\prime \prime} \sum_{m=0}^{i} H_{i-m}^{\prime} H_{m}^{\prime} \\ +\frac{9}{\delta} \sum_{i=0}^{j-1} H_{j-1-i}^{\prime} \sum_{m=0}^{i} H_{i-m}^{\prime} \sum_{y=0}^{m} H_{m-y}^{\prime} H_{y}^{\prime} \\ +\frac{\delta}{16} \sum_{i=0}^{j-1} H_{j-1-i}^{\prime \prime} \sum_{m=0}^{i} H_{i-m}^{\prime \prime} \sum_{y=0}^{m} H_{m-y}^{\prime \prime} H_{y}^{\prime \prime}\end{array}\right)$

$\mathcal{R}_{\phi}^{j}=\phi_{j-1}^{\prime \prime}+\operatorname{SrSc} \theta_{j-1}^{\prime \prime}-\operatorname{Re} \operatorname{Le} \operatorname{Pr} \sum_{i=0}^{j-1} H_{i} \phi_{j-1-i}^{\prime}$

On solving Eq. (35) along with Eq. (36), the analytical solution for velocity, temperature and concentration profiles are obtained. Unlike all other analytic methods, the HAM make available a simple mode to regulate the rate of approximations and control the convergence region of the series solution, ensured by taking the most suitable value of the non-zero auxiliary parameter $\hbar$. Consequently, the auxiliary parameter shows vital role in the frame of the HAM which can be defined by the so-called $\hbar$-curves. For this purpose $\hbar$-curves are plotted in Fig. (2) which shows the admissible range.

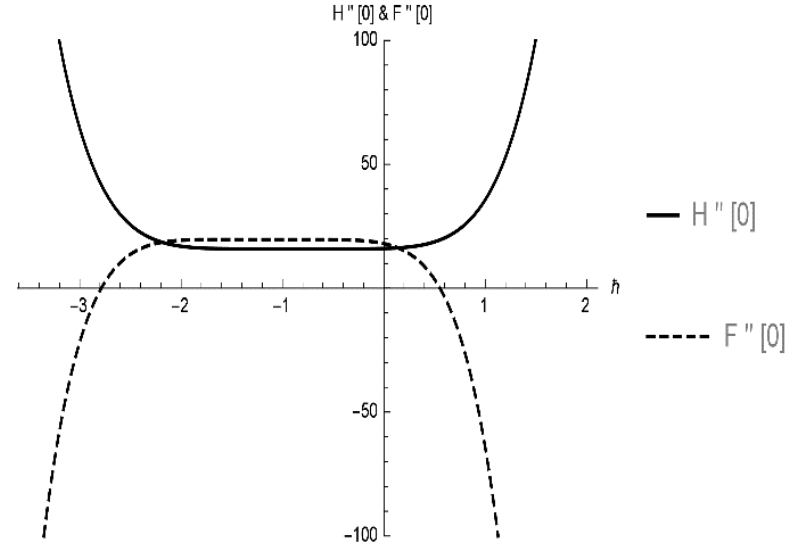

Fig. 2. $\hbar$ curves

\section{DISCUSSION OF RESULTS}

In this section, we present our findings i.e. the influence of pertinent parameters on velocity, temperature, pressure and concentration fields, in graphical form along with their interpretation. Also, graphical representations of entropy generation and Bejan number have presented to see the behavior of involved parameters. The considered mathematical flow problem has been defined in Eqs. (12), (13) and (16) together with the boundary conditions Eq. (15) and (17) have been solved analytically via HAM. Obtained results of the velocity and temperature fields have been used to compute the entropy generation and Bejan number. Exhibited results showing a comparison between HAM solutions with those generated by using optimized HAM. To validate the results comparison was made. An excellent correspondence between two methods is achieved, as seen in Figures 3-6.

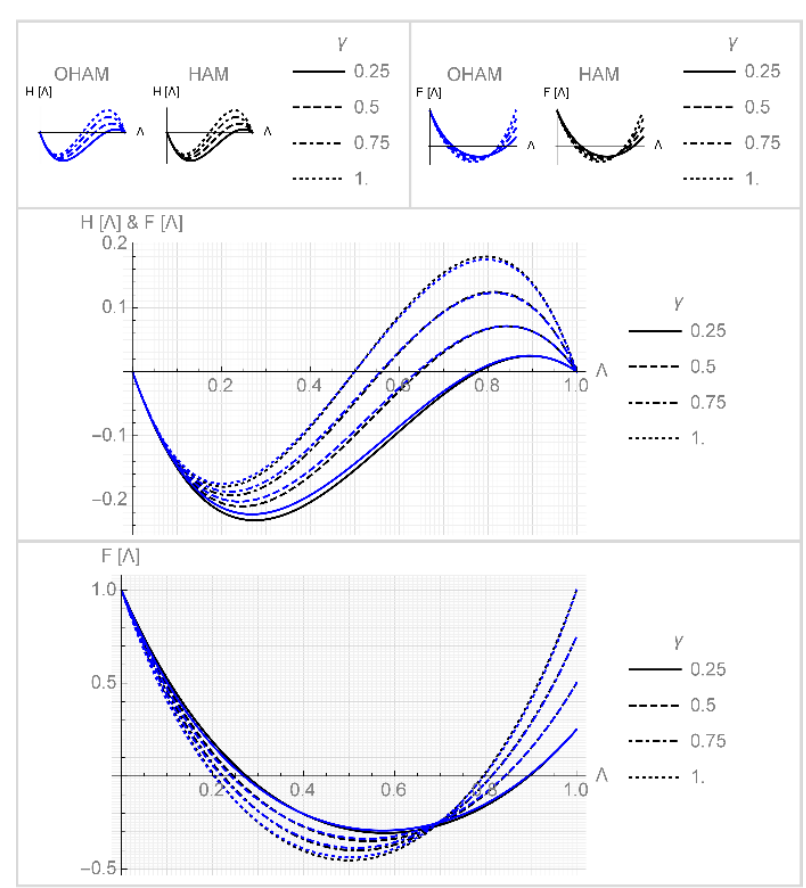

Fig. 3. Effect of $\gamma$ on $\mathrm{F}(\Lambda)$ and $\mathrm{H}(\Lambda)$ with $\delta=0.1, H a=2, R e=5, L=0.1, N=0.1$ 


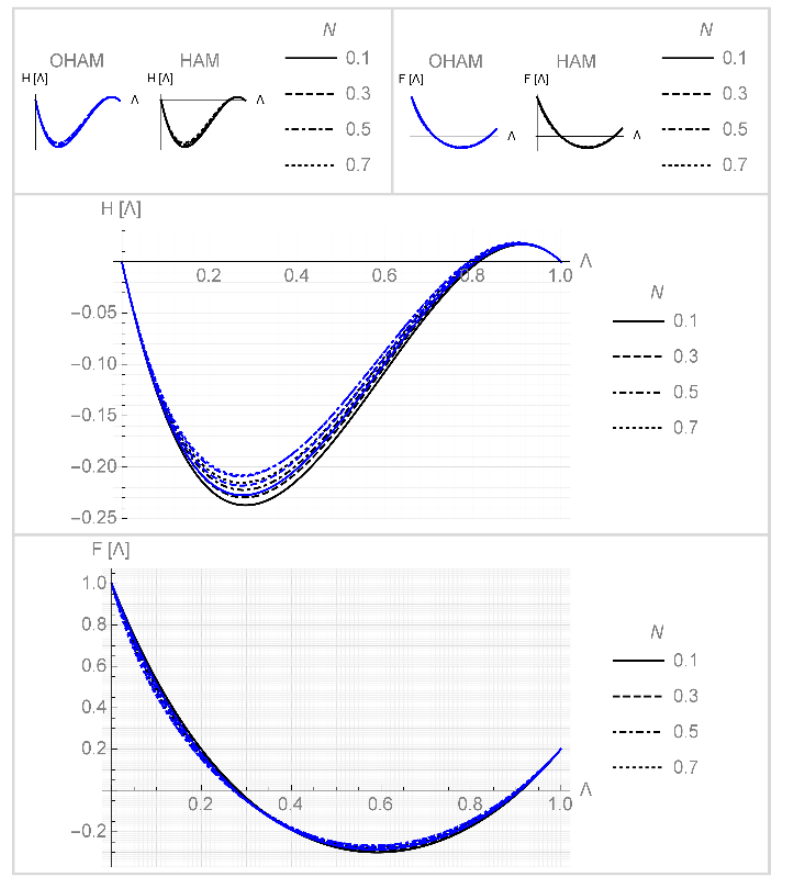

Fig. 4. Effect of $\mathrm{N}$ on $\mathrm{F}(\Lambda)$ and $\mathrm{H}(\Lambda)$ with $\delta=0.1, H a=2, R e=5, L=0.1, \gamma=0.2$

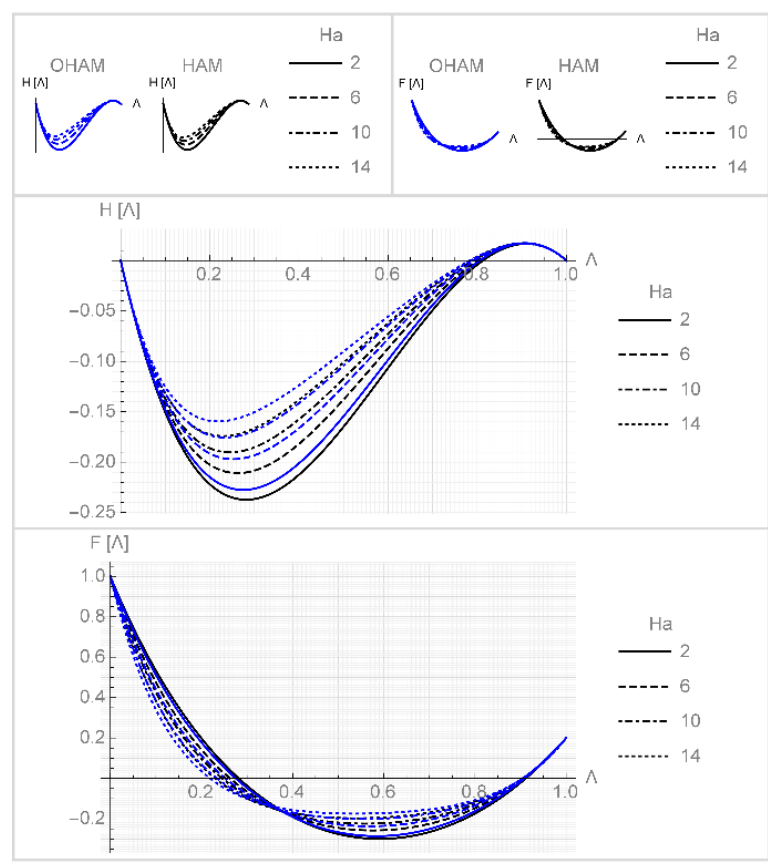

Fig. 5. Effect of $\mathrm{Ha}$ on $\mathrm{F}(\Lambda)$ and $\mathrm{H}(\Lambda)$ with

$$
\delta=0.1, \gamma=0.2, \operatorname{Re}=5, L=0.1, N=0.1
$$

Figs. 3-6 are sketched to see the variations of the PowellEyring parameter $N$, stretching disk parameter $\gamma$, Hartmann number $\mathrm{Ha}$ and Reynolds number Re on dimensionless velocity profiles in radial $F(\Lambda)$ and axial direction $H(\Lambda)$. Fig. 3 clarifies that dimensionless $H(\Lambda)$ declines first and then starts to increase due to increase in $N$ and at upper disk it gets vanish, after attaining certain values while dimensionless $F(\Lambda)$ decreases and it increases gradually. For $\gamma$ Fig. 4 elucidates that the increment in $\gamma$ declines first and then rapidly rises $H(\Lambda)$ and at the upper disk it dies out, however, diminutions near lower disk and maximum amplification nearby upper disk in $F(\Lambda)$ can be seen. Fig. 5 de- picts that the magnitude of $H(\Lambda)$ gets weakens adjacent to the lower disk as the Ha increases. Behind this Lorentz force is the reason, which opposes the motion of fluid. Further, it slowly increases and approaches to zero. $F(\Lambda)$ decreases with the rise in $\mathrm{Ha}$ and after getting some point it starts increasing. As the increase in Re results the increase in $H(\Lambda)$, therefore the viscosity of Powell-Eyring fluid decreases and stretching of disks have not been considerably influential for a less viscous fluid. Whereas $F(\Lambda)$ decreases first and when the Re increase enough it starts increasing (see Fig. 6). It is quite obvious from all the graphs of $H(\Lambda)$ that axial velocity at lower disk decreases and it turns into a radial component of the disk and also it disappears at the upper disk.

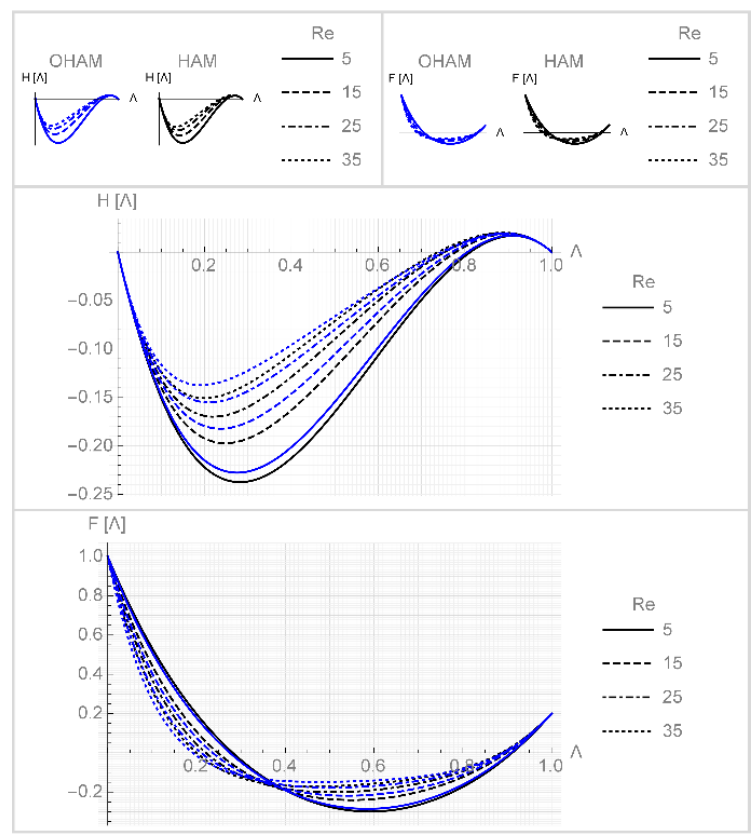

Fig. 6. Effect of Re on $\mathrm{F}(\Lambda)$ and $\mathrm{H}(\Lambda)$ with $\delta=0.1, H a=2, \gamma=0.2, L=0.1, N=0.1$

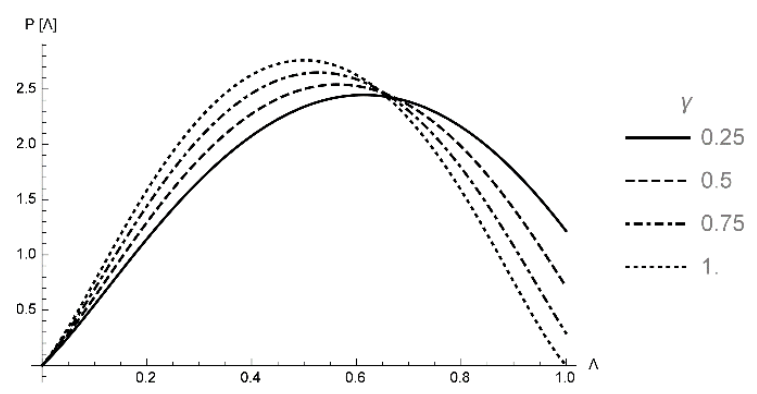

Fig. 7. Effect of $\gamma$ on $P(\Lambda)$ with $\delta=0.1, H a=2, R e=5, L=0.1, N=0.1$

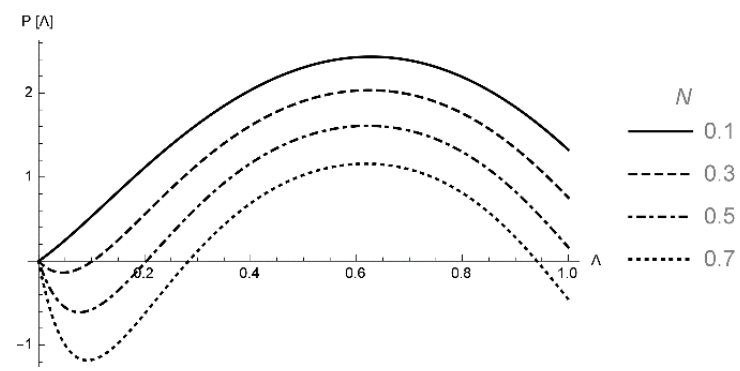

Fig. 8. Effect of $\mathrm{N}$ on $\mathrm{P}(\Lambda)$ with $\delta=0.1, H a=2, \operatorname{Re}=5, L=0.1, \gamma=0.2$ 


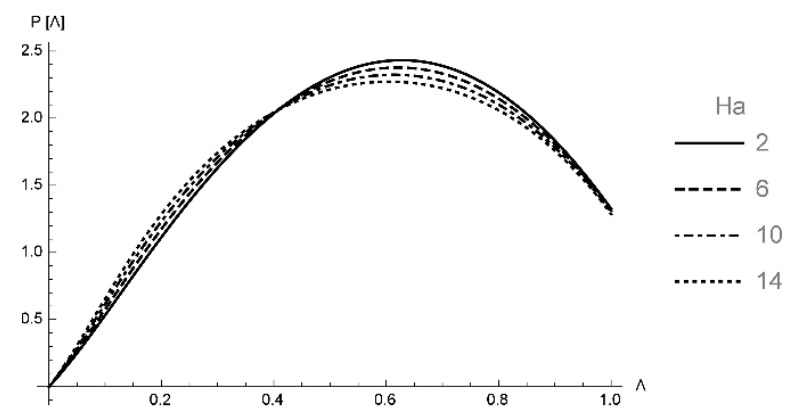

Fig. 9. Effect of Ha on $\mathrm{P}(\Lambda)$ with $\delta=0.1, \gamma=0.2, R e=5, L=0.1, N=0.1$

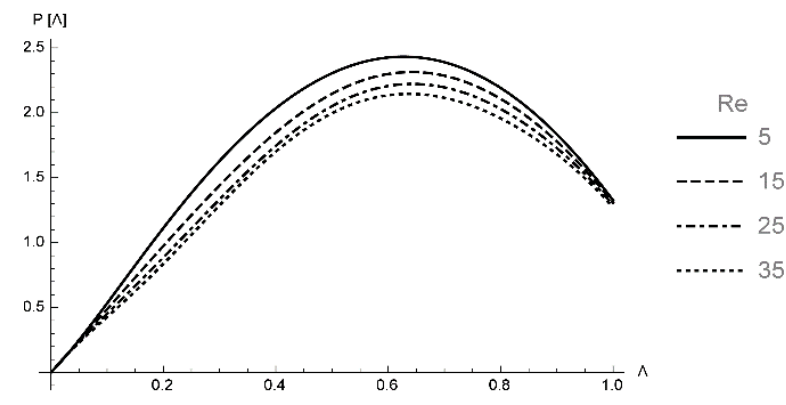

Fig. 10. Effect of $\operatorname{Re}$ on $\mathrm{P}(\Lambda)$ with $\delta=0.1, H a=2, \gamma=0.2, L=0.1, N=0.1$

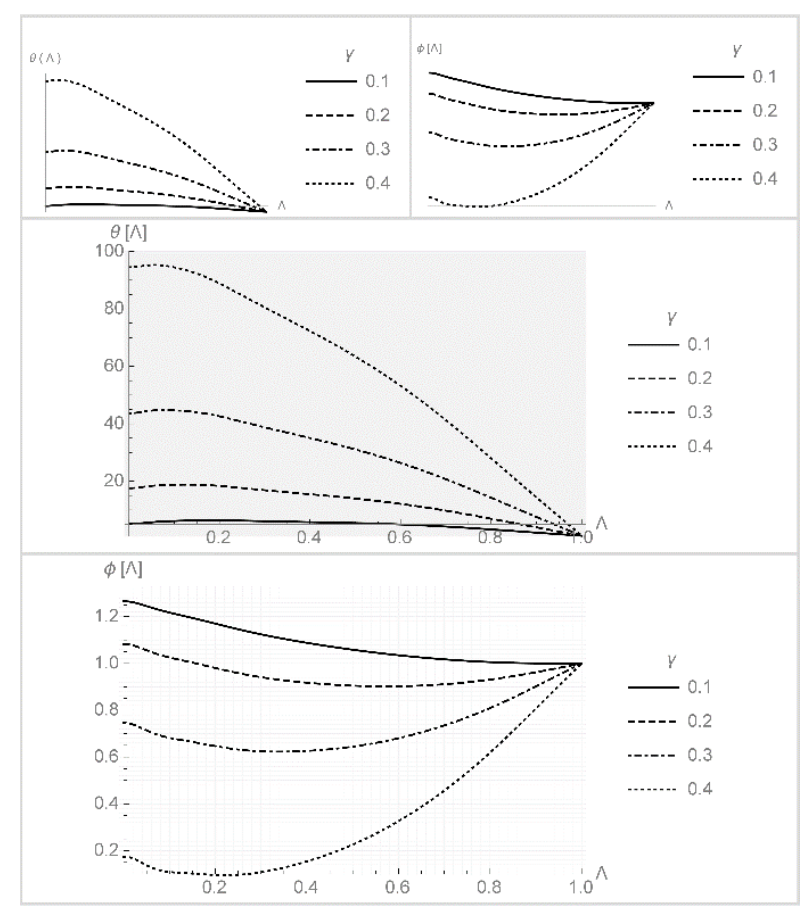

Fig. 11. Effect of $\gamma$ on $\theta(\Lambda)$ and $\phi(\Lambda)$ with

$\delta=0.1, \mathrm{Du}=0.5, \mathrm{Le}=1, \mathrm{Ha}=2, \mathrm{Sc}=0.3, \mathrm{Sr}=0.4$, $\operatorname{Re}=1, \operatorname{Pr}=0.7, \mathrm{Br}=0.14, L=0.1, N=5$

Fig. 7-10 reveals the effects of the various parameter against pressure profile $(\Lambda)$. It is illustrated by Figs. 7-8 that $P(\Lambda)$ becomes strengthen as $\gamma$ and Ha enhances but after reaching the particular point it comes to drop. An increase in $\mathrm{N}$ and $\mathrm{Re}, \mathrm{P}(\Lambda)$ turn out to be diminished as shown in Figs. 9-10.

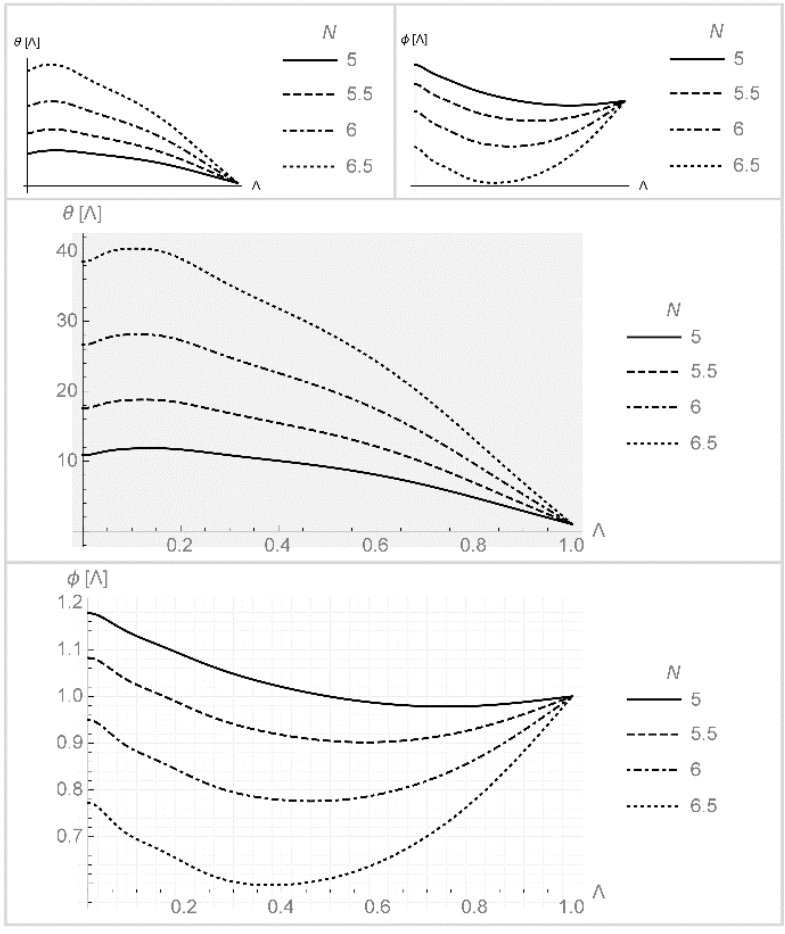

Fig. 12. Effect of $\mathrm{N}$ on $\theta(\Lambda)$ and $\phi(\Lambda)$ with $\delta=0.1, D u=0.5, L e=1, H a=2, S c=0.3, S r=0.4$, $R e=1, \operatorname{Pr}=0.7, B r=0.14, L=0.1, \gamma=0.2$

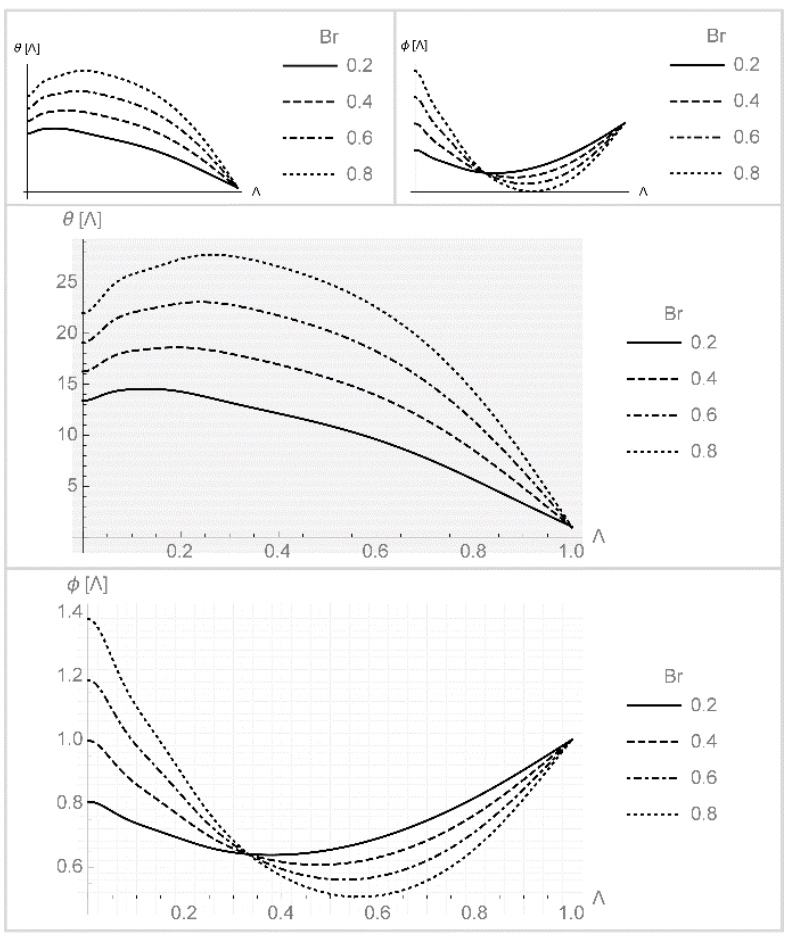

Fig. 13. Effect of $\operatorname{Br}$ on $\theta(\Lambda)$ and $\phi(\Lambda)$ with

$$
\begin{aligned}
& \delta=0.1, D u=0.5, L e=1, H a=2, S c=0.3, S r=0.4, \\
& R e=5, \operatorname{Pr}=0.7, N=5, L=0.1, \gamma=0.2
\end{aligned}
$$

Effects of flow parameters on temperature $\theta(\Lambda)$ and concentration $\phi(\Lambda)$ fields are displayed in Figs. 11-20. The effect of $\gamma$ and $\mathrm{N}$ on $\theta(\Lambda)$ and $\phi(\Lambda)$ are given in Figs. 11 and 12. These figures illustrate that an increment in $N$ and $\gamma$ accelerates $\theta(\Lambda)$ and decelerates $\phi(\Lambda)$. According to Figs. 13 as Brinkman number intensifies $\theta(\Lambda)$ also intensify on the other hand $\phi(\Lambda)$ first 
increases near the lower disk and then starts to decline and at the upper disk it gets constant. In Fig. 14-15 it can be observed that due to increase in $\operatorname{Pr}$ and $\operatorname{Re}, \theta(\Lambda)$ rises due to this thickness of thermal boundary layer and reduces $\phi(\Lambda)$.

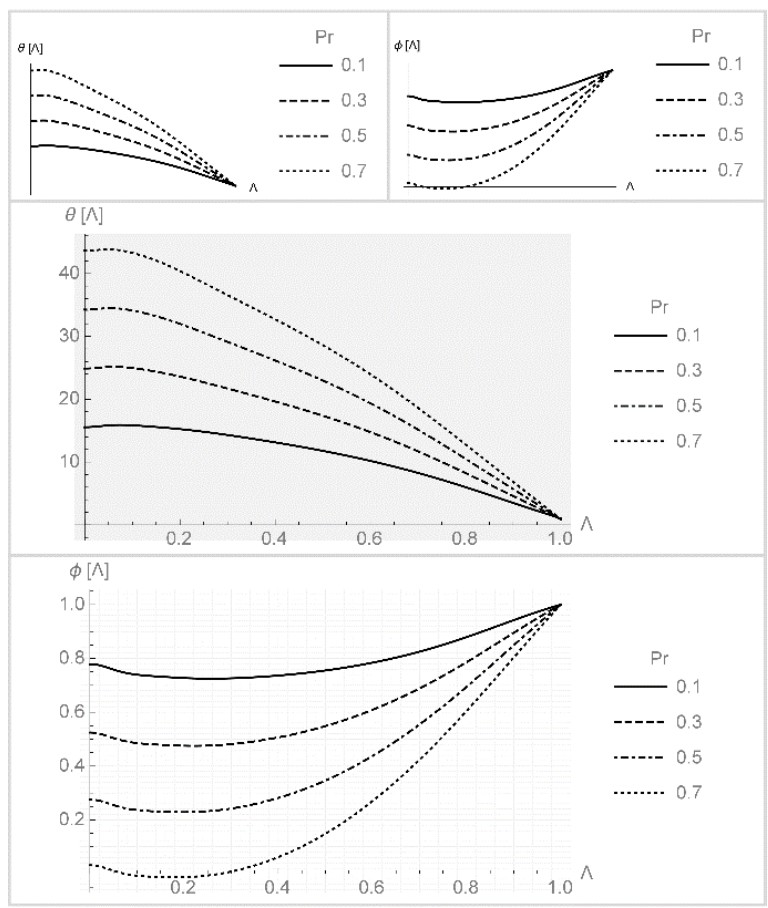

Fig. 14. Effect of $\operatorname{Pr}$ on $\theta(\Lambda)$ and $\phi(\Lambda)$ with

$\delta=0.1, D u=0.5, L e=1, H a=2, S c=0.3, S r=0.4$, $R e=5, \gamma=0.5, B r=0.14, L=0.1, N=5$

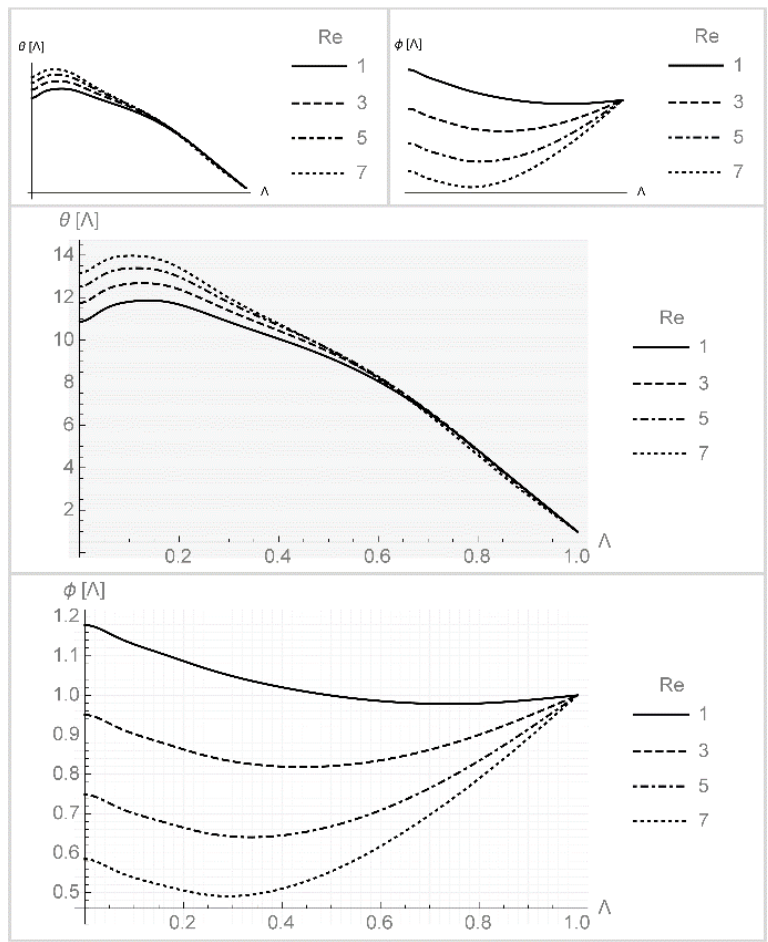

Fig. 15. Effect of $\operatorname{Re}$ on $\theta(\Lambda)$ and $\phi(\Lambda)$ with $\delta=0.1, D u=0.5, L e=1, H a=2, S c=0.3, S r=0.4$, $\gamma=0.2, \operatorname{Pr}=0.7, B r=0.14, L=0.1, N=5$

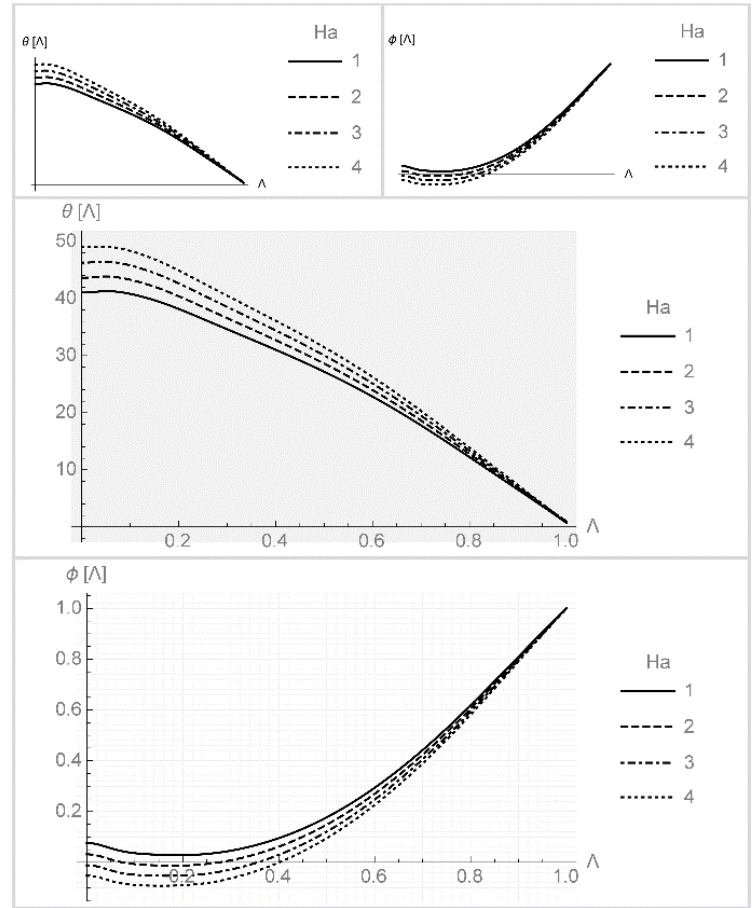

Fig. 16. Effect of Ha on $\theta(\Lambda)$ and $\phi(\Lambda)$ with

$$
\delta=0.1, D u=0.5, L e=1, \gamma=0.5, S c=0.3, S r=0.4 \text {, }
$$$$
R e=5, \operatorname{Pr}=0.7, B r=0.14, L=0.1, N=5
$$

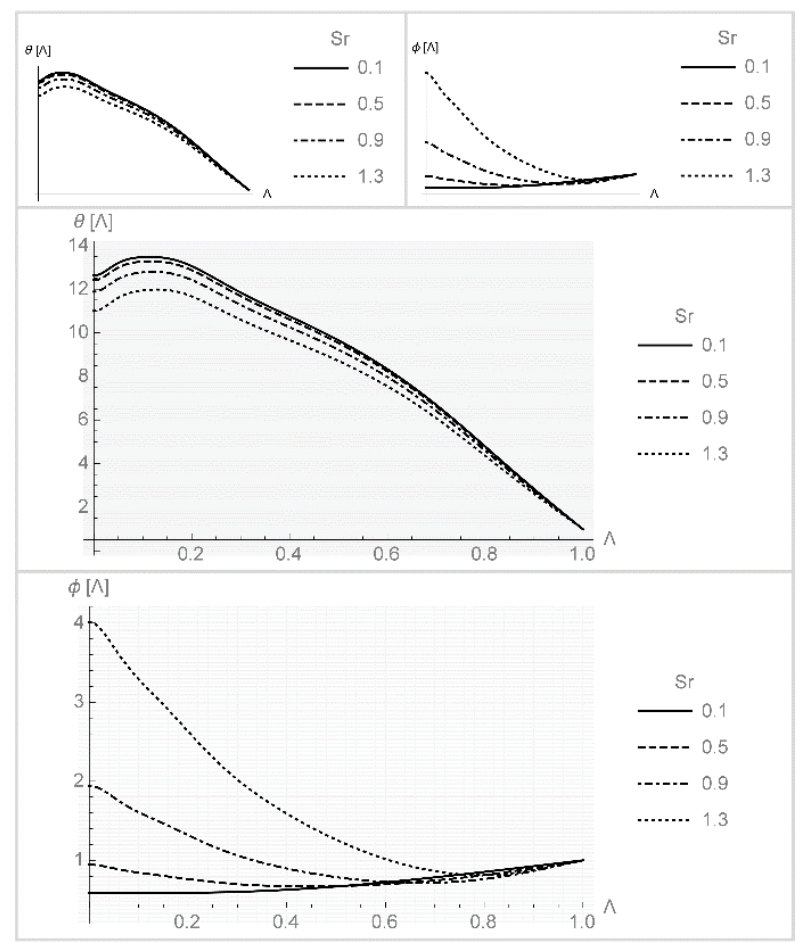

Fig. 17. Effect of Sc on $\theta(\Lambda)$ and $\phi(\Lambda)$ with $\delta=0.1, D u=0.5, L e=1, H a=2, \gamma=0.2, S r=0.3$, $\operatorname{Re}=5, \operatorname{Pr}=0.7, B r=0.14, L=0.1, N=5$

Since a drag force has the effect of decay and ultimately thickening of the thermal boundary layer and reduction in $\phi(\Lambda)$ having noticed as the Ha gets stronger (see Fig. 16). Similar effects have been observed for Soret and Schmidt number from Figs. 17 and 18. For large amounts of Soret and Schmidt number $\theta(\Lambda)$ is larger and these numbers have the thickening effect on 
thermal boundary layer, however, $\phi(\Lambda)$ has its maximum value at the lower disk and drops near the upper disk. Fig. 19 and 20 depict that the effect of Dufour and Lewis number are alike. With the increase in Dufour and Lewis number $\theta(\Lambda)$ come to enhance and $\phi(\Lambda)$ becomes depreciated.

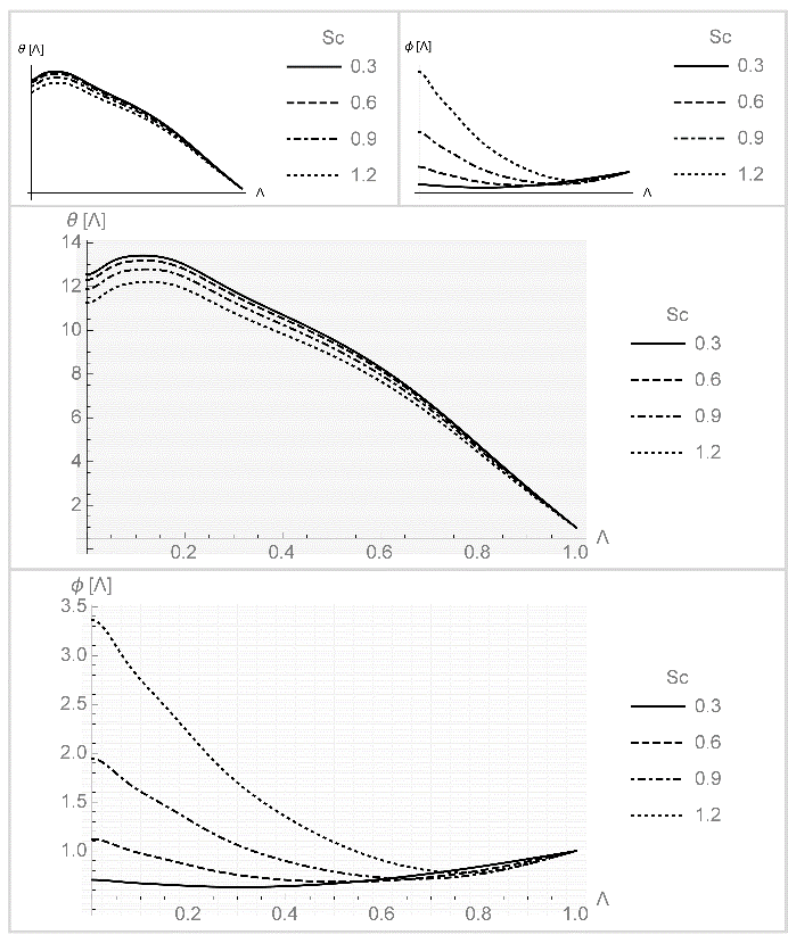

Fig. 18. Effect of $\operatorname{Re}$ on $\theta(\Lambda)$ and $\phi(\Lambda)$ with

$\delta=0.1, D u=0.5, L e=1, H a=2, S c=0.3, S r=0.4$, $\gamma=0.2, \operatorname{Pr}=0.7, B r=0.14, L=0.1, N=5$

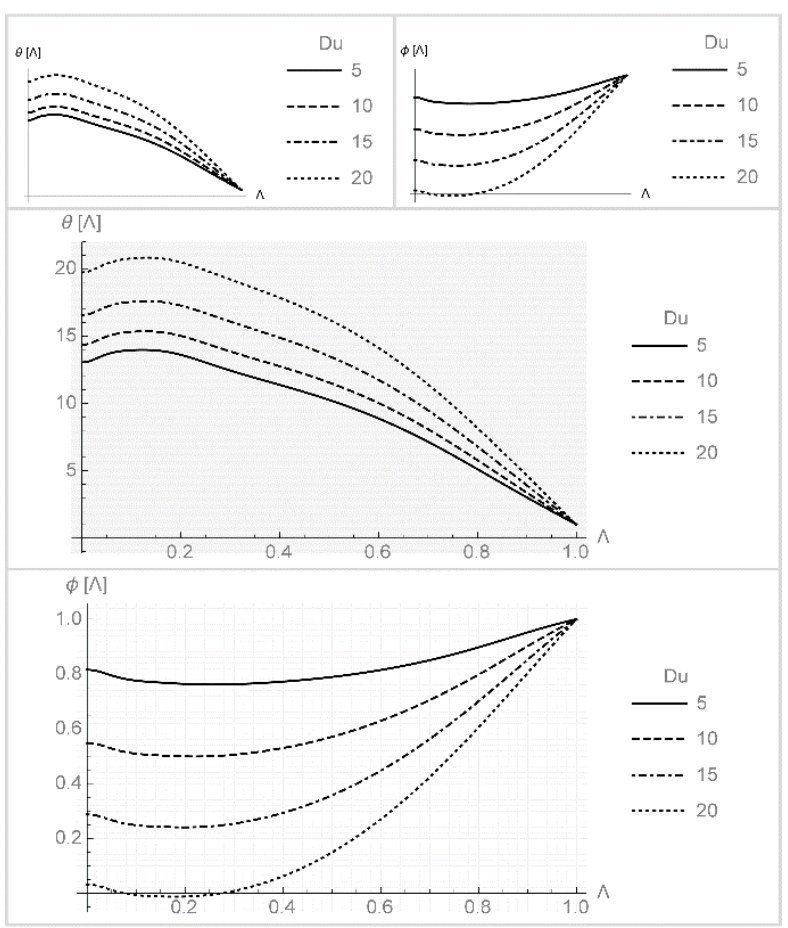

Fig. 19. Effect of Le on $\theta(\Lambda)$ and $\phi(\Lambda)$ with

$\delta=0.1, D u=0.5, \gamma=0.2, H a=2, S c=0.3, S r=0.4$, $R e=5, P r=0.7, B r=0.14, L=0.1, N=5$

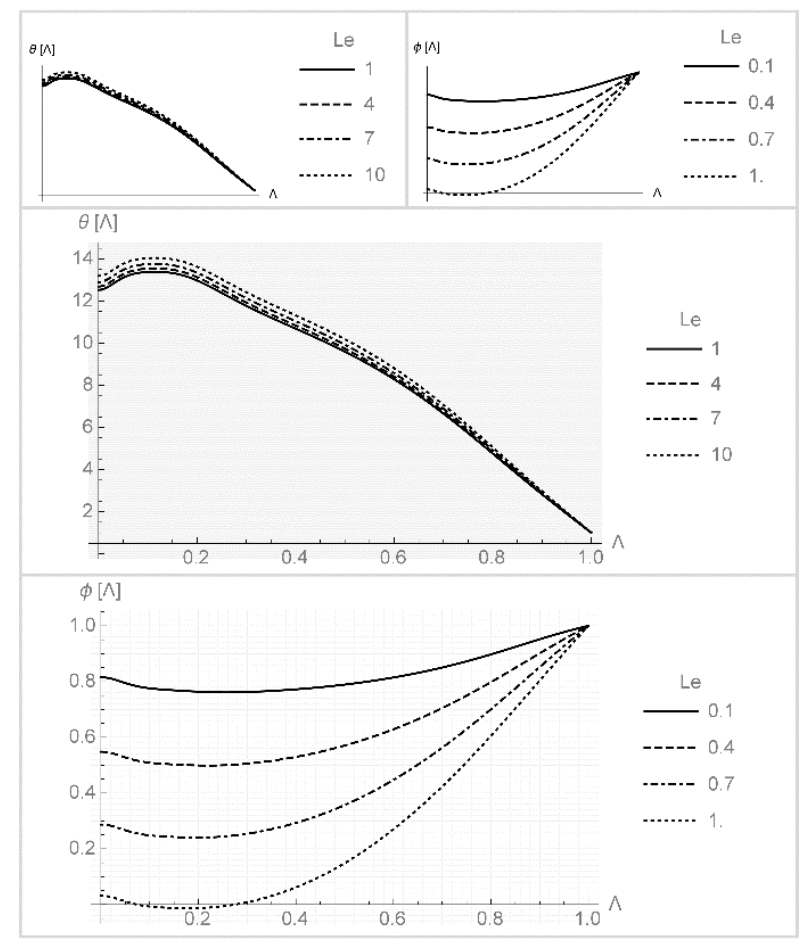

Fig. 20. Effect of $\mathrm{Du}$ on $\theta(\Lambda)$ and $\phi(\Lambda)$ with

$\delta=0.1, \gamma=0.2, L e=1, H a=2, S c=0.3, S r=0.4$,

$\operatorname{Re}=5, \operatorname{Pr}=0.7, B r=0.14, L=0.1, N=5$

The variation in entropy generation number $N_{G}$ and Bejan number Be are plotted in Fig. 21-25.

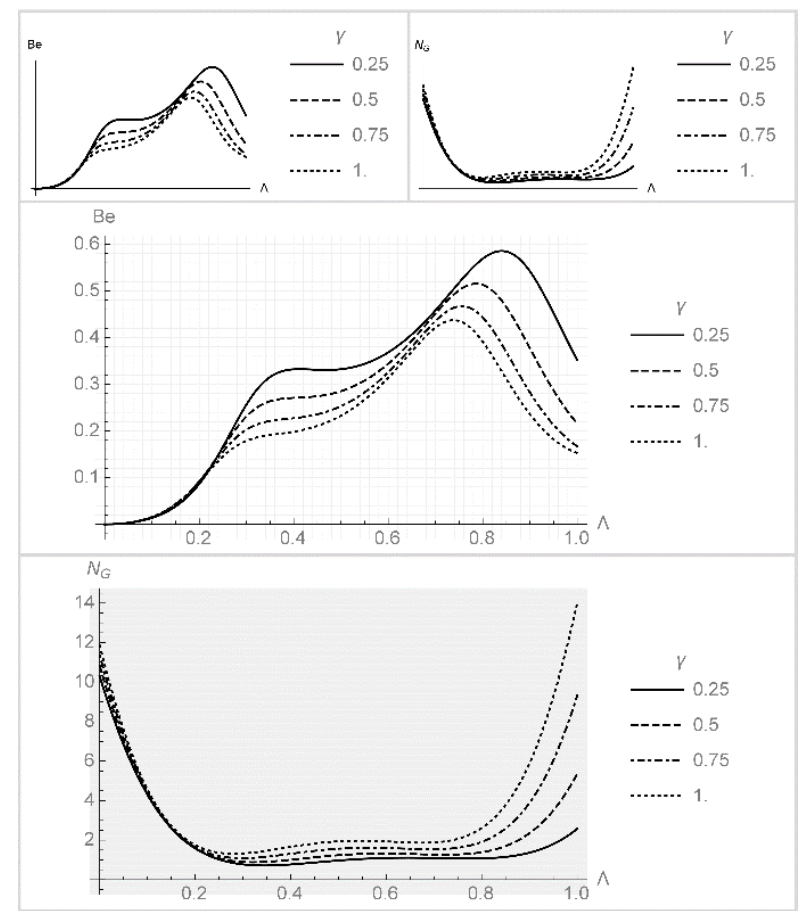

Fig. 21. Effect of $\gamma$ on $\mathrm{N}_{\mathrm{G}}$ and Be with

$\delta=0.3, \lambda=0.4, D u=0.5, L e=0.1, S c=0.1, S r=0.2$, $B r=0.14, \operatorname{Pr}=0.7, H a=2, R e=5, L=0.1, N=0.1$ 


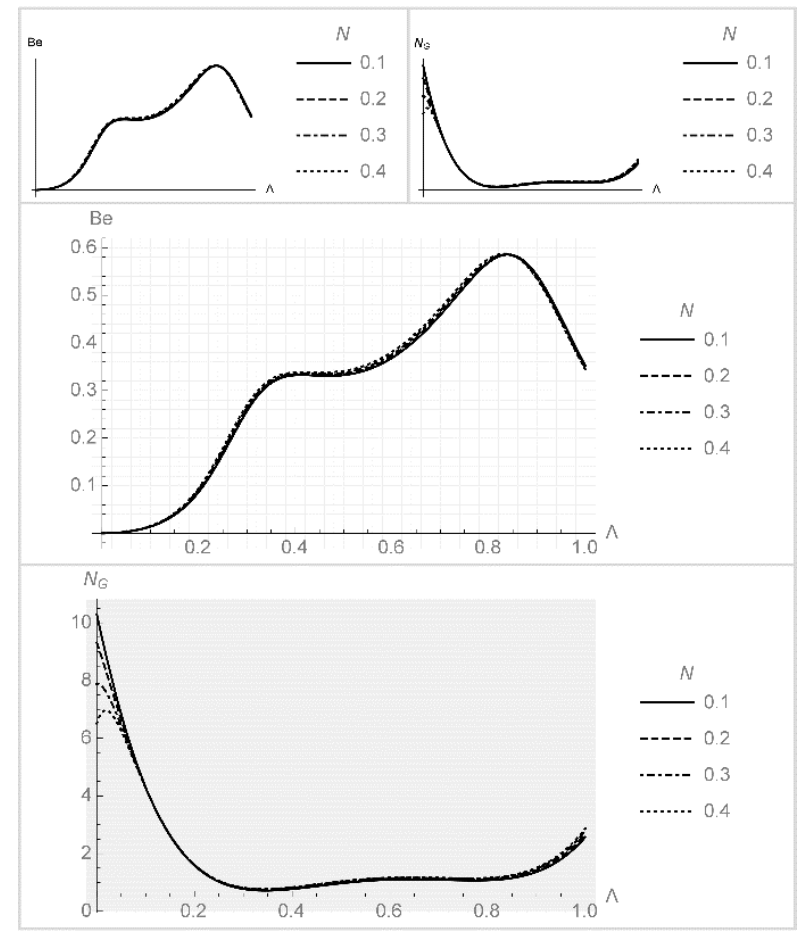

Fig. 22. Effect of $\mathrm{N}$ on $\mathrm{N}_{\mathrm{G}}$ and Be with $\delta=0.3, \lambda=0.4, D u=0.5, L e=0.1, S c=0.1, S r=0.2$, $B r=0.14, \operatorname{Pr}=0.7, H a=2, R e=5, L=0.1, \gamma=0.25$

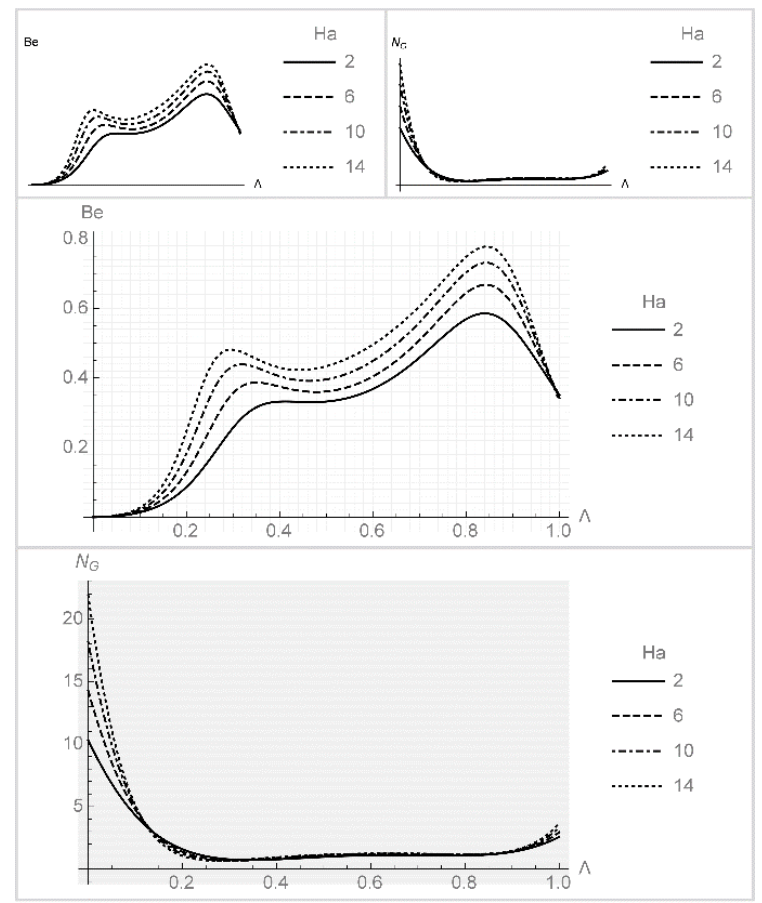

Fig. 23. Effect of $\mathrm{Ha}$ on $\mathrm{N}_{\mathrm{G}}$ and $\mathrm{Be}$ with

$\delta=0.3, \lambda=0.4, D u=0.5, L e=0.1, S c=0.1, S r=0.2$, $B r=0.14, \operatorname{Pr}=0.7, \gamma=0.25, \operatorname{Re}=5, L=0.1, N=0.1$

As $\gamma$ gets stronger, entropy generation also gets stronger and energy loss is maximized at the lower and upper disk but flatten in between the disk. Although the Bejan number increases as $\gamma$ augments and declines as one goes downstream. Near the lower disk variation in $\mathrm{Be}$ due to $\gamma$ are negligible but farther than in the flow regime entropy effect due to fluid friction and magnetic field becomes fully dominant (see Fig. 21). Fig. 22 shows $\mathrm{N}_{\mathrm{G}}$ is maximum at lower disk due to stretching of the disk, and decreases as the $\mathrm{N}$ increases far away but at the upper disk, it slowly increases. Further, Be gradually increases thus entropy effect due to heat transfer gets strong and near the upper disk, it comes to weak. Fig. 23 illustrates that as Ha gets stronger, energy loss is maximum at the lower disk and far away the disk energy loss steadily decreases but at the upper disk it increases a little bit. Moreover, from the same figure, it can be seen that due to $\mathrm{Ha}$ intensification effect of entropy due to heat transfer becomes clearly prominent.

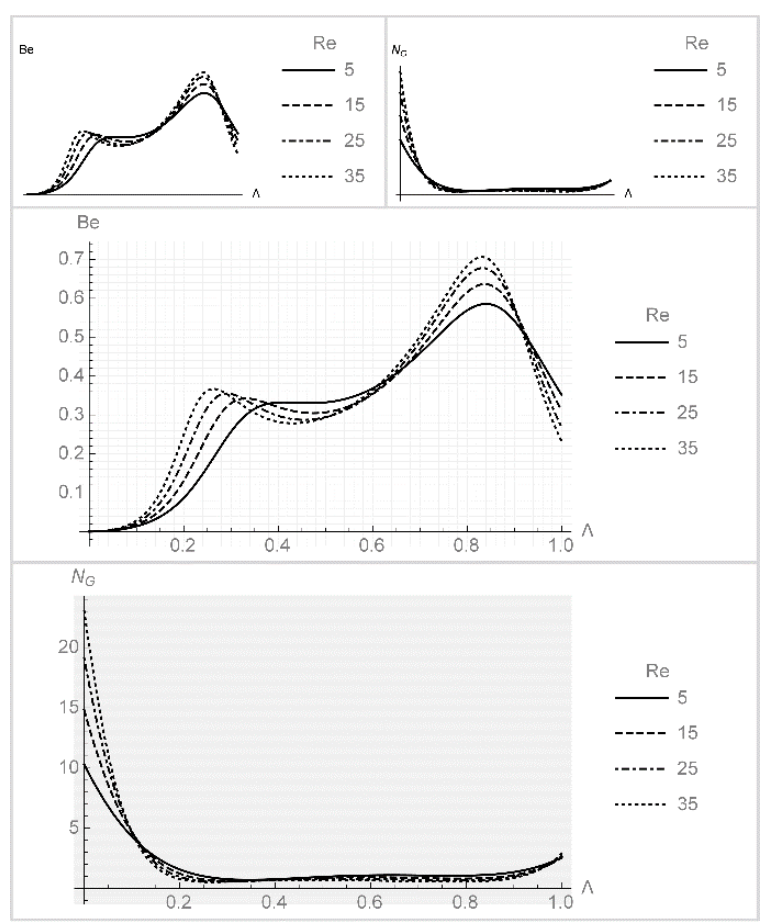

Fig. 24. Effect of $\operatorname{Re}$ on $\mathrm{N}_{\mathrm{G}}$ and $\mathrm{Be}$ with

$\delta=0.3, \lambda=0.4, D u=0.5, L e=0.1, S c=0.1, S r=0.2$, $B r=0.14, P r=0.7, H a=2, \gamma=0.25, L=0.1, N=0.1$

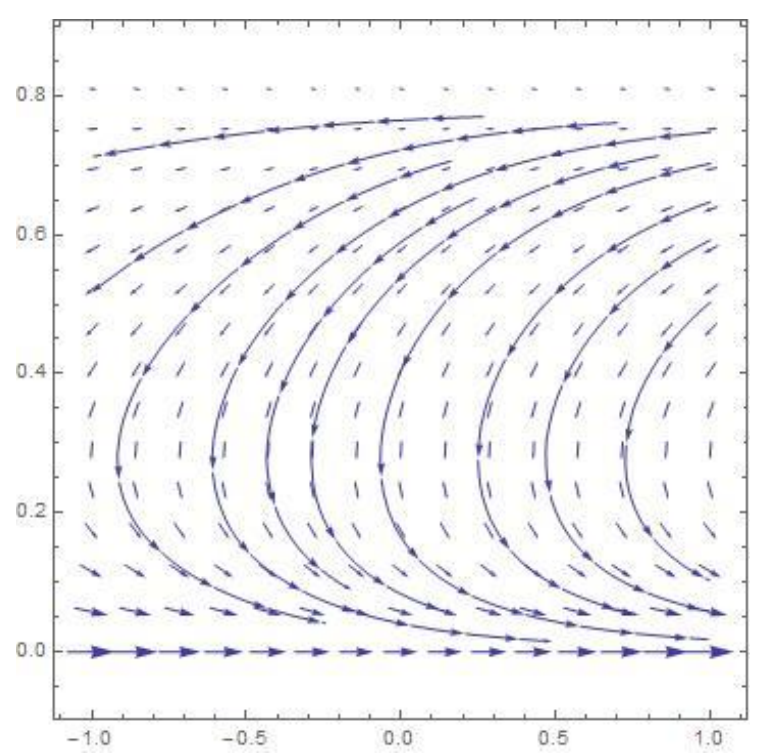

Fig. 25. Velocity vector $\mathrm{u}$ for $=0.25,0.50$,

$\delta=0.3, \lambda=0.4, D u=0.5, L e=0.1, S c=0.1, S r=0.2$, $B r=0.14, P r=0.7, R e=5, L=0.1, N=0.1$ 
Due to an increase in Re entropy generation has larger value at the lower disk, but as it moves farther from the lower disk it shows the reverse behavior as portray in Fig.24. The effects of Re on $\mathrm{Be}$ are also shown in Fig. 24 for large Re two different trends are noticed. The effect of fluid heat transfer irreversibility dominates over fluid friction and magnetic field irreversibility near the surface of the lower disk as the Re increases while far away in the flow regime, the heat transfer irreversibility lessen. Furthermore, fluid friction and magnetic field irreversibility again become stronger whereas at upper disk the heat transfer irreversibility becomes strong and fully dominant. Fig. 25 and 26 are depicted for velocity components $\mathrm{u}, \mathrm{w}$ for different stretching parameters $\gamma=0.25,0.5$ respectively.

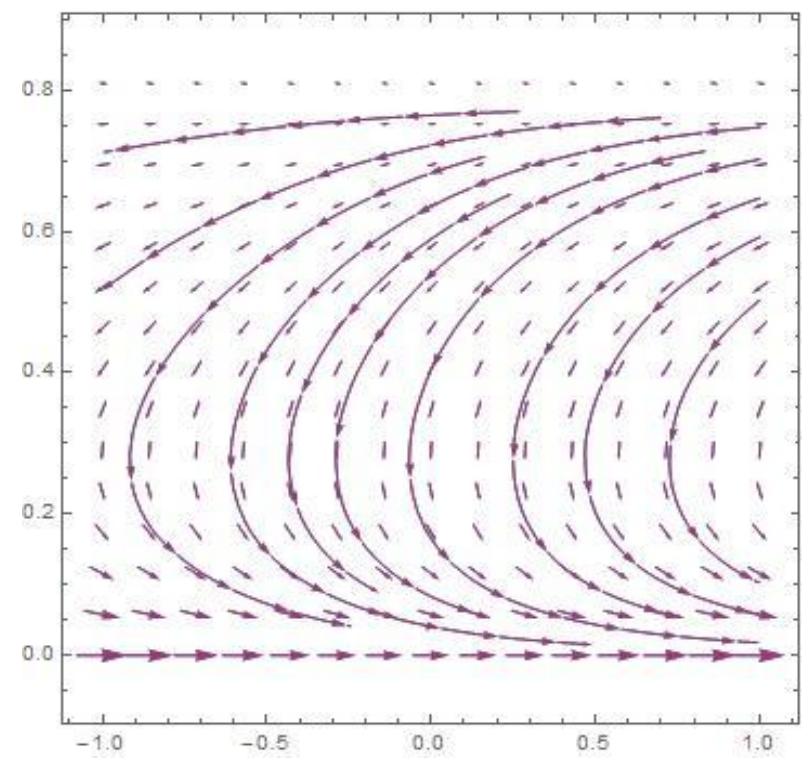

Fig. 26. Velocity vectors wfor $\gamma=0.25,0.50$,

$\delta=0.3, \lambda=0.4, D u=0.5, L e=0.1, S c=0.1, S r=0.2$, $B r=0.14, \operatorname{Pr}=0.7, \operatorname{Re}=5, L=0.1, N=0.1$

The comparison between our results and the results reported by Gorder et al. (2009). When we put $N=0, L=0$ Eq. (16) it will reduces for the Newtonian fluid as Gorder et al. (2009) have presented.

\section{CONCLUSION}

The present study is focused on the analytical exploration of the flow and entropy generation characteristics associated with the steady laminar incompressible flow of Powell-Eyring fluid between two stretching rotating disks in the presences of applied magnetic field. The magnetic field is taken as constant and acting only in the axial direction. The system of the nonlinear ordinary differential equation derived after using appropriate similarity functions. HAM has applied to solve the arising nonlinear ODEs and a comparison with the results obtained from OHAM have been made to corroborate the results which were obtained by HAM. An excellent confirmation of results has observed. Acquired results were sketched graphically and the effects of pertinent parameters discussed thoroughly. For the considered problem Skin friction coefficient and local Nusselt number were represented mathematically. Entropy generation and Bejan number were also rendered and presented explicitly for the different values of involved parameters.

In this study acquired results concluded in such a manner that these will use to improve the optimality and efficiency of a thermally designed flow system and to reduce the energy loss within the system by taking the suitable values of flow parameters.

\section{REFERENCES}

1. Abolbashari M.H., Freidoonimehr N., Nazari F., Rashidi M.M. (2014), Entropy analysis for an unsteady MHD flow past a stretching permeable surface in nano-fluid, Powder Technology, 267, 256-267.

2. Afify A.A. (2009), Similarity solution in MHD: effects of thermal diffusion and diffusion thermo effects on free convective heat and mass transfer over a stretching surface considering suction or injection, Communications in Nonlinear Science and Numerical Simulation, 14 2202-2214.

3. Anjali Devi S.P., Uma Devi R. (2011), Soret and Dufour effects on MHD slip flow with thermal radiation over a porous rotating infinite disk, Communications in Nonlinear Science and Numerical Simulation, 16, 1917-1930.

4. Ariel P.D. (2001), Axisymmetric Flow of a Second Grade Fluid Past a Stretching Sheet, International Journal of Engineering Science, 39, 529-553.

5. Arikoglu A., Ozkol I. (2008), Komurgoz G. Effect of slip on entropy generation in a single rotating disk in MHD flow, Appl. Energy, 85, 1225-1236.

6. Asghar S., Jalil M., Hussan M., Turkyilmazoglu M. (2014), Lie group analysis of flow and heat transfer over a stretching rotating disk, International Journal of Heat and Mass Transfer, 69, 140-146.

7. Ashraf M., Batool K. (2013), MHD flow and heat transfer of a micropolar fluid over a stretchable disk, Journal of Theoretical and Applied Mechanics, 51, 25-38.

8. Banks W. (1983), Similarity solutions of the boundary-layer equations for a stretching wall, Journal de. Mécaniqe, Théorique et Appliquee, 2, 375-392.

9. Bataller R.C. (2007), Viscoelastic fluid flow and heat transfer over a stretching sheet under the effects of a non-uniform heat source, viscous dissipation and thermal radiation, International Journal of Heat and Mass Transfer, 50, 3152-3162.

10. Bejan A. (1982), Entropy generation through heat fluid flow, $2^{\text {nd }}$ ed., New York, Wiley.

11. Bejan A. (1996), Entropy generation minimization: the method of thermodynamic optimization of finite-size systems and finite-time processes, CRC Press.

12. Bhatti M.M., Abbas T., Rashidi M.M., Ali M.E.S. (2016), Numerical Simulation of Entropy Generation with Thermal Radiation on MHD Carreau nanofluid towards a Shrinking Sheet, Entropy, 18(6), 200.

13. Butt A.S., Ali A. (2014), Entropy analysis of magnetohydrodynamic flow and heat transfer due to a stretching cylinder, Journal of Taiwan institute of chemical engineers, 45, 780-786.

14. Butt A.S., Munawar S., Ali A., Mehmood A. (2012), Entropy generation in hydrodynamic slip flow over a vertical plate with convective boundary, Journal of Mechanical Science and Technology, 26, 2977 2984

15. Crane L.J. (1970), Flow past a stretching plate, ZAMP, 21, 645-647.

16. Eckert E.R.G., Drake R.M. (1972), Analysis of heat and mass transfer, New York: McGraw-Hill.

17. Fang T. (2007), Flow over a stretchable disk, Physics of Fluids, 19 , 128105.

18. Fang T., Zhang J. (2008), Flow between two stretchable disks-an exact solution of the Navier-Stokes equations, International Communication of Heat and Mass Transfer, 35, 892-895.

19. Gaikwad S.N., Malashetty M.S., Prasad Rama K. (2007), An analytical study of linear and nonlinear double diffusive convection with Soret and Dufour effects in couple stress fluid, International Journal of Non-Linear Mechanics, 42, 903-913. 
20. Gorder R.V., Sweet E., Vajravelu K. (2010), Analytical solutions of a coupled nonlinear system arising in a flow between stretching disks, Applied Mathematics and Computation, 216, 1513-1523.

21. Grubka L.J., Bobba K.M. (1985), Heat transfer characteristic of a continuous stretching surface with variable temperature, International Journal of Heat and Mass Transfer, 107, 248-250.

22. Guo J., Xu M., Cai J., Huai X. (2011), Viscous dissipation effect on entropy generation in curved square microchannels, Energy, 36, 5416-5423.

23. Gupta P., Gupta A. (1977), Heat and mass transfer on a stretching sheet with suction or blowing, Candian Journal of Chemical Engineers, 55, 744-746.

24. Hayat T., Mustafa M., Pop I. (2010), Heat and mass transfer for Soret and Dufour's effect on mixed convection boundary layer flow over a stretching vertical surface in a porous medium filled with a viscoelastic fluid, Communications in Nonlinear Science and Numerical Simulation, 15, 1183-1196.

25. Khan N.A., Aziz S., Khan N.A. (2014), MHD flow of Powell-Eyring fluid over a rotating disk, Journal of the Taiwan Institute of Chemical Engineers, 45, 2859-2867.

26. Khan N.A., Aziz S., Khan N.A. (2014), Numerical Simulation for the Unsteady MHD Flow and Heat Transfer of Couple Stress Fluid over a Rotating Disk, Plos One..

27. Li X., Faghri A. (2011), Local entropy generation analysis on passive high-concentration DMFCs (direct methanol fuel cell) with different cell structures, Energy, 36, 403-414.

28. Liao S.J. (2003), Beyond Perturbation: Introduction to the Homotopy Analysis Method, Chapman \& Hall CRC Press, Boca Raton.

29. Liao S.J. (2004), On the Homotopy Analysis Method for nonlinear problems, Applied Mathematics and Computation, 147, 499-513.

30. Mahian O., Oztop H., Pop I. Mahmud S., Wongwises S. (2013), Entropy generation between two vertical cylinders in the presence of MHD flow subjected to constant wall temperature, International Communications in Heat and Mass Transfer, 44, 87-92.

31. Munawar S., Mehmood A., Ali A. (2011), Effects of slip on flow between two stretchable disks using optimal homotopy analysis method, Canadian Journal of Applied Sciences, 1, 50-68.

32. Osalusi E., Side J., Harris R. (2008), Thermal-diffusion and diffusion-thermo effects on combined heat and mass transfer of a steady MHD convective and slip flow due to a rotating disk with viscous dissipation and Ohmic heating, International Journal of Heat and Mass Transfer, 35, 908-915.

33. Parvin S., Chamkha A.J. (2014), An analysis on free convection flow, heat transfer and entropy generation in an odd-shaped cavity filled with nanofluid, International Communications in Heat and Mass Transfer, 54, 8-17.

34. Powell R.E., Eyring H. (1944), Mechanism for the relaxation theory of viscosity, Nature, 154, 427-428.

35. Rashidi M.M., Hayat T., Erfani E., Mohimanian Pour S.A., Awatif Hendi A. (2011), Simultaneous effects of partial slip and thermaldiffusion and diffusion-thermo on steady MHD convective flow due to a rotating disk, Communications in Nonlinear Science and Numerical Simulation, 16, 4303-4317.

36. Rashidi M.M., Kavyani N., Abelman S. (2014), Investigation of entropy generation in MHD and slip flow over a rotating porous disk with variable properties, International Journal of Heat and Mass Transfer, 70, 892-917.
37. Sajid M., Hayat T., Ayub M. (2008), Series Solution for Unsteady Axisymmetric Flow and Heat Transfer over a Radially Stretching Sheet, Communications in Nonlinear Science and Numerical Simulation, 13, 2193-2202.

38. Sakiadis B.C. (1961), Boundary layer behavior on continuous solid surfaces: I boundary layer on a continuous flat surface, AICHE J., 7, 221-225.

39. Shateyi S., Motsa S.S., Makukula Z. (2015), On Spectral Relaxation Method for Entropy Generation on a MHD Flow and Heat Transfer of a Maxwell Fluid, Journal of Applied Fluid Mechanics, 8, 21-31.

40. Torabi M., Zhang K. (2015), Heat transfer and thermodynamic performance of convective- radiative cooling double layer walls with temperature-dependent thermal conductivity and internal heat generation, Energy Conversion and Management, 89, 12-23

41. Tsai R., Huang J.S. (2009), Heat and mass transfer for Soret and Dufour's effects on Hiemenz flow through porous medium onto a stretching surface, International Journal of Heat and Mass Transfer, 52, 2399-2406.

42. Turkyilmazoglu M. (2012), MHD fluid flow and heat transfer due to a stretching rotating disk, International Journal of Thermal Science, 51, 195-201.

43. Wang C.Y. (1984), The three-dimensional flow due to a stretching flat surface, Physics of Fluids, 27, 1915.

44. Wang C.Y. (1988), Stretching a surface in a rotating fluid, Journal of Applied Mathematics and Physics, ZAMP, 39, 177-185.

Nomenclature: $B$ - Magnetic flux density (T), Be - Bejan number, $\mathrm{Br}$ - Brinkman number, $C$ - Concentration of fluid $\left(\mathrm{m}^{-3} \mathrm{~mol}\right)$, $\mathrm{C}_{1}, \mathrm{C}_{2}, \ldots . \mathrm{C}_{8}-$ Arbitrary constants, $\mathrm{C}_{\mathrm{f}}-$ Coefficient of skin friction, $\mathrm{Cp}$ - Specific heat at constant pressure $\left(\mathrm{N} \mathrm{m} \mathrm{kg}^{-1} \mathrm{~K}^{-1}\right)$, Cs - Concentration susceptibility of fluid, Dm - Molecular diffusion coefficient, Du - Dufour number, Ec - Eckert number, $F, G, H$ - Dimensionless radial, tangential and axial velocities, Ha - Hartmann number, Kt - Thermal diffusion ratio, $L$ - Powell-Eyring parameter, $\mathcal{L}$ - Auxiliary linear operator, Le - Lewis number, $N$ - Powell-Eyring Parameter, $N_{G}$ - Entropy generation number, $\mathrm{N}_{\mathrm{u}}$ - Nusselt number, $P$ - Dimensionless pressure, $\mathrm{Re}-$ Wall stretching Reynolds number, $\mathrm{Re}_{m}$ - Magnetic Reynolds number, $S_{i j}$ - Extra stress tensor of Powell-Eyring fluid, Sc - Schmidt number, $\mathrm{Sr}$ - Soret number, $S_{G}-$ Volumetric entropy generation rate $\mathrm{J} \mathrm{K}^{-1}$, $\mathrm{S}_{\mathrm{G} 0}$ - Characteristic entropy generation rate $\left(\mathrm{J} \mathrm{K}^{-1}\right), T-$ Temperature of fluid $(\mathrm{K}), \mathrm{T}_{\mathrm{m}}$ - Mean fluid temperature $(\mathrm{K}), \boldsymbol{V}$ - Velocity of fluid $\left(\mathrm{m} \mathrm{s}^{-1}\right), b$ - Material constant for Powell-Eyring fluid, $c$ - Distance between two disks (m), $k$ - Thermal conductivity of fluid $\left(\mathrm{W} \mathrm{m} \mathrm{m}^{-1} \mathrm{~K}^{-1}\right.$ ), $l$ - Stretching disk parameter, $p$ - Pressure of fluid (Pa), $q$ - Embedding parameter, $r, \psi, z$ - Coordinate axes, $u, v, w-$ Dimensional $r, \psi$ and $z$ components of velocity $\left(\mathrm{m} \mathrm{s}^{-1}\right)$, $\alpha$ - Fluid thermal diffusivity $\left(\mathrm{m}^{2} \mathrm{~s}^{-1}\right), \varepsilon$ - Material constant for PowellEyring fluid, $\gamma$ - Ratio of stretching velocity of the upper disk to the lower disk, $\delta$ - Dimensionless ratio of the radius of the disk to the distance between them, $\hbar$ - Auxiliary non-zero operator, $\eta$ - Unknown parameter, $\mu$ - Dynamic viscosity of fluid $\left(\mathrm{Kg} \mathrm{m}^{-1} \mathrm{~s}^{-1}\right), v-$ Kinematic viscosity $\left(\mathrm{m}^{2} \mathrm{~s}^{-1}\right), \Omega$ - Angular velocity of disk $\left(\mathrm{s}^{-1}\right), \phi$ - Dimensionless concentration of fluid, $\theta$ - Dimensionless temperature of fluid, $\rho$ - Density of fluid $\left(\mathrm{Kg} \mathrm{m}^{-3}\right), \sigma$ - Electric conductivity $\left(\Omega^{-1} \mathrm{~m}^{-1}\right)$. 